\title{
Oscillatory brain activity and maintenance of verbal and visual working memory: a systematic review
}

\author{
Yuri G. Pavlov ${ }^{1,2}$, Boris Kotchoubey ${ }^{1}$
}

${ }^{1}$ Institute of Medical Psychology and Behavioral Neurobiology, University of Tübingen, 72076, Germany

${ }^{2}$ Department of Psychology, Ural Federal University, Department of Psychology, Ekaterinburg, 620000, Russian Federation

Running head: Rhythms of working memory: a systematic review

Corresponding author:

Yuri G. Pavlov

Email: pavlovug@gmail.com

Address: Institute of Medical Psychology and Behavioral Neurobiology, University of Tübingen, 72076, Germany 


\section{Abstract}

Brain oscillations likely play a significant role in the storage of information in working memory (WM). Despite the wide popularity of the topic, current attempts to summarize the research in the field are narrative reviews. We address this gap by providing a descriptive systematic review, in which we investigated oscillatory correlates of maintenance of verbal and visual information in WM. The systematic approach enabled us to challenge some common views popularized by previous research. The identified literature (100 EEG/MEG studies) highlighted the importance of theta oscillations in verbal WM: frontal midline theta enhanced with load in most verbal studies, while more equivocal results have been obtained in visual studies. Increasing WM load affected alpha activity in most studies, but the direction of the effect was inconsistent: the ratio of studies that found alpha increase versus decrease with increasing load, was $80 / 20 \%$ in the verbal WM domain and close to $60 / 40 \%$ in the visual domain. Alpha asymmetry (left $<$ right) was a common finding in both verbal and visual WM studies. Beta and gamma activity studies yielded the least convincing data: a diversity in spatial and frequency distribution of beta activity prevented us from making a coherent conclusion; gamma rhythm was virtually neglected in verbal WM studies with no systematic support for sustained gamma changes during the delay in EEG studies in general. 


\section{Introduction}

Working memory (WM) is the ability to maintain and manipulate information for a short period of time (Baddeley, 2003). The temporal structure of WM can be subdivided into a period of information encoding, maintenance, and retrieval. The maintenance interval (delay period) is a defining component of WM differentiating it from other types of memory.

Dissecting the temporal structure of WM delay using behavioral measures as well as by employment of functional magnetic resonance imaging (fMRI) is compounded with a lot of assumptions and limitations (Gitelman, Penny, Ashburner, \& Friston, 2003; Lindquist, Meng Loh, Atlas, \& Wager, 2009; Steinbrink et al., 2006). Behavioral measures such as reaction time and accuracy only reflect the result of information processing in WM. fMRI studies of WM focus on the spatial distribution of activation in the brain and have limited time resolution.

Qualitatively different types of information about WM are available from M/EEG (magneto-/electroencephalography) signals. Brain oscillations derived from M/EEG play an important role in human cognition and represent an energy-efficient mechanism for communication within the brain (Buzsaki, 2004; Fell \& Axmacher, 2011). An important question is how different oscillations relate to the maintenance of information in WM. The neural activity that persists over the delay period is a subject of extensive research in psychology (D’Esposito \& Postle, 2015).

At a first glance, the amount of literature on oscillatory mechanisms supporting WM performance is enormous. The excessive amount of literature may be one reason why there is no systematic review on this wide topic. Previous numerous attempts to summarize the findings in the field have led to a few influential narrative reviews (Hsieh \& Ranganath, 2014; Klimesch, 1999; Roux \& Uhlhaas, 2014; van Ede, 2018). Despite their impactful role in advancing the field, the data in narrative reviews can be selectively reported, favoring the most visible studies, or focusing on studies supporting the narrative (Bushman \& Wells, 2001; Pae, 2015). While we acknowledge that there is a place for both types of research synthesis - systematic and narrative reviews - most researchers in the field will likely agree that a comprehensive review of the extant findings is needed for building theories and searching for oscillatory mechanisms 
underlying WM. In the present review, we did not select data to support or reject any theoretical claims. We aimed to provide a systematic overview of the empirical findings in two domains of WM - a panoramic view on the state of the art in research on verbal and visual WM.

Being a cross-modal construct, WM can depend on stimulus modality (Baddeley, Hitch, \& Allen, 2019; Daniel, Katz, \& Robinson, 2016; Postle, 2006). A non-exhaustive list of the differences between verbal and visual WM may include the speed of memory decay, spatial and temporal distribution of associated neural activity, and the time of encoding and consolidation (Oberauer et al., 2018). A somewhat special place of verbal WM has been identified in a collaborative expert report summarizing the findings in WM research (Oberauer et al., 2018). Therefore, one can expect that some findings would differ between visual and verbal WM. To characterize the generalizability versus specificity of the findings in verbal and visual modalities, we compared the descriptive information between the corresponding studies.

The main objective of the review was to systematically study oscillatory activity during maintenance of verbal and visual information in WM in healthy young individuals under normal conditions.

\section{Methods}

\subsection{Search strategy}

Two databases (Pubmed and Web of Science) were included in the search. The first author extracted data from the records. A first search was conducted with the query (meg OR magnetoencephalography OR eeg OR electroencephalography OR electrophysiolog*) AND ((working memory) OR (short-term memory)) on 22.04.2019. The second search with the same query was conducted on 02.01.2020 and restricted to 2019 and 2020 publication years. The results were amended by screening references in the articles identified in the databases search, and in review articles. 


\subsection{Definition of the eligibility criteria}

Among verbal WM tasks, the n-back task is one of the most frequently used. In a n-back task a continuous sequence of items (e.g., letters or digits) is presented to the participant. At the presentation of each display, the participant makes the decision with a button press whether the item in the current display matches the item presented $\mathrm{N}$ displays back. Thus, in the 1-back task, the participant has to compare the stimulus being currently displayed and the immediately previous stimulus stored in memory and press the button if the two are identical.

In the n-back task, memory-related brain activity is confounded with the activity related to the motor response. Therefore, the results of the time-frequency analysis obtained in studies employing this paradigm are likely to be biased. Alpha/beta activity related to the preparation of the response and the rebound after its execution overlaps with the activity related to the maintenance of information in WM and decision making (Pesonen, Hämäläinen, \& Krause, 2007). For instance, Chen \& Huang (2015) reported a significant effect of WM load on the activity in the beta frequency band. However, the difference in the onset of beta activity between 1-back and 2-back conditions was the same as the difference in reaction time between the two conditions. Beta suppression latency in the n-back task correlated with reaction time in another study (Palomaki, Kivikangas, Alafuzoff, Hakala, \& Krause, 2012). Therefore, the effect observed by the authors is more likely to be related to the preparation of the response than to WM processes. Even using longer inter-stimulus intervals (ISI) as in Deiber et al. (2007) (3.5 s) does not protect from the rebound of alpha-beta activity after the response. Even if no response trials are analyzed, the EEG activity may be contaminated by response suppression. The difficulty in the isolation of directly WM related cognitive operations makes the task hardly suitable for EEG. Therefore, only studies with a clear separation between maintenance and other cognitive operations were included in the review. All n-back studies were excluded.

Patterns of oscillatory activity obtained from EEG, MEG and intracranial EEG (iEEG) data can be similar. However, some differences exist (Leijten, Huiskamp, Hilgersom, \& van Huffelen, 2003; Malmivuo, 2012; Sharon, Hämäläinen, Tootell, Halgren, \& Belliveau, 2007; Stefan et al., 1994). Particularly, a number of properties make iEEG studies less generalizable. First, the sample of human iEEG studies is much smaller than that of 
studies using MEG and EEG. Second, physical properties of the signal are different, because more local neuronal populations are recorded by means of iEEG. Third, iEEG is most frequently recorded in epilepsy patients. The patients regularly take painkillers while recovering from the implantation of electrodes, they also stop taking antiepileptic drugs to provoke seizures. The mild cognitive impairment that may take place in this population requires the cognitive tasks to be modified accordingly. For these reasons, we decided to exclude iEEG literature from the analysis.

Oscillatory brain activity during the delay was the focus of the review. Short delay periods, typical for some EEG research, may complicate the interpretation of the findings in the context of numerous behavioral studies. Furthermore, the first few hundred milliseconds after a stimulus are usually covered by phase-locked evoked and eventrelated responses (ERP), which were explicitly not the target of the present work. In this review, we aimed to study sustained oscillatory brain activity as opposed to transient short-lived oscillatory surges elicited by the stimulus onset.

Therefore, we included in the analysis only WM studies with the delay period equal to or longer than $1 \mathrm{~s}$. This inclusion criterion will not give a full guarantee that the sustained oscillatory activity is not contaminated by ERP. We consider this decision a reasonable trade-off to include as many studies as possible to the review to increase the sample size while avoiding mixing up different processes with different underlying mechanisms.

\subsection{Screening on eligibility criteria abstracts/titles}

Inclusion criteria:

1. EEG or MEG study

2. human subjects

3. study oscillatory brain activity

4. population of healthy young adults

Exclusion criteria:

1. animal research

2. ERP study 


\section{3. iEEG study}

4. special population (such as children, elderly, patients, etc.)

6. motor (e.g. sequential motor task), tactile, or auditory WM task

7. mathematical modeling or methods paper

8. review, editorial, letter to the editor

9. brain stimulation studies (e.g., transcranial electric stimulation, transcranial magnetic stimulation (TMS))

10. interventional study (e.g., the influence of physical exercise, alcohol, caffeine, nicotine consumption, or other drugs)

11. concurrent real-life tasks (e.g., driving, flight simulator, jogging, cycling)

\subsection{Full texts screening and data extraction}

The inclusion/exclusion criteria were refined to satisfy the objective to study oscillatory activity during the maintenance of information in WM. To achieve this goal, we extracted data on absolute or relative spectral power in theta $(\sim 4-8 \mathrm{~Hz})$, alpha ( 8-13 Hz), beta $(\sim 13-30 \mathrm{~Hz})$, and gamma $(>30 \mathrm{~Hz})$ frequency bands. Delta frequency band was not included.

Brain oscillations are characterized not only by frequency but also by spatial distribution. Among different types of theta rhythms, the most closely related to the current work theta is frontal midline theta (FMT) rhythm. In the rest of the manuscript, any mention of theta rhythm or FMT will refer to frontal midline theta unless stated otherwise. Similarly, alpha activity, when the separation was possible, was sourced from posterior cortical areas (as opposed, for example, to central or frontal alpha). We did not restrict our analyses of beta and gamma activity to particular spatial locations.

An inclusion criterion that was difficult to infer from the abstracts was the type of analysis. Only those studies were included where spectral power was calculated and statistical output was reported. If one article comprised multiple experiments in different samples, they were treated as independent studies. In the opposite situation, if an article used the dataset reported in another article, the article was either excluded or combined 
with the previous one into a single study if the results were complementary. In some of the studies, the delay period was not analyzed statistically but we were able to infer the absence or existence of the effects from the figures (e.g., using bar graphs or distribution of spectral power in time with reported measurement error). These studies were also included in the review if at least 1 sec of the visual depiction was presented.

Verbal information can be presented auditorily or visually. However, since we aimed to explore the generalizability and specificity of WM modality, verbal WM studies were included only if the information was presented visually.

Thus, the additional inclusion criteria were:

1. the task should follow a model with a separate delay period

2. the duration of the delay interval should be longer than or equal to $1 \mathrm{~s}$. As a consequence, the studies were excluded in which the duration of delay was not reported.

3. spectral power in either theta, alpha, beta, or gamma frequency band during the delay period should be analyzed (e.g., studies reporting only index of lateralized alpha activity were excluded)

4. the analyzes should include a comparison either with baseline or between levels of WM load

5. type of WM task: verbal or visual (visuo-spatial)

6. the information is presented visually

Exclusion criteria:

1. connectivity analysis

2. machine learning studies

3. concurrent activity during the delay (n-back task, distractors, mental manipulations)

\section{Results}

The full sample of 100 studies is presented in Table 1 (verbal WM) and Table 2 (visual WM). The flow chart with stages of the selection process is depicted in Figure 1 . The 100 
articles included 100 studies: one article had two datasets (studies), and one study was published in two articles.

First search

Second search

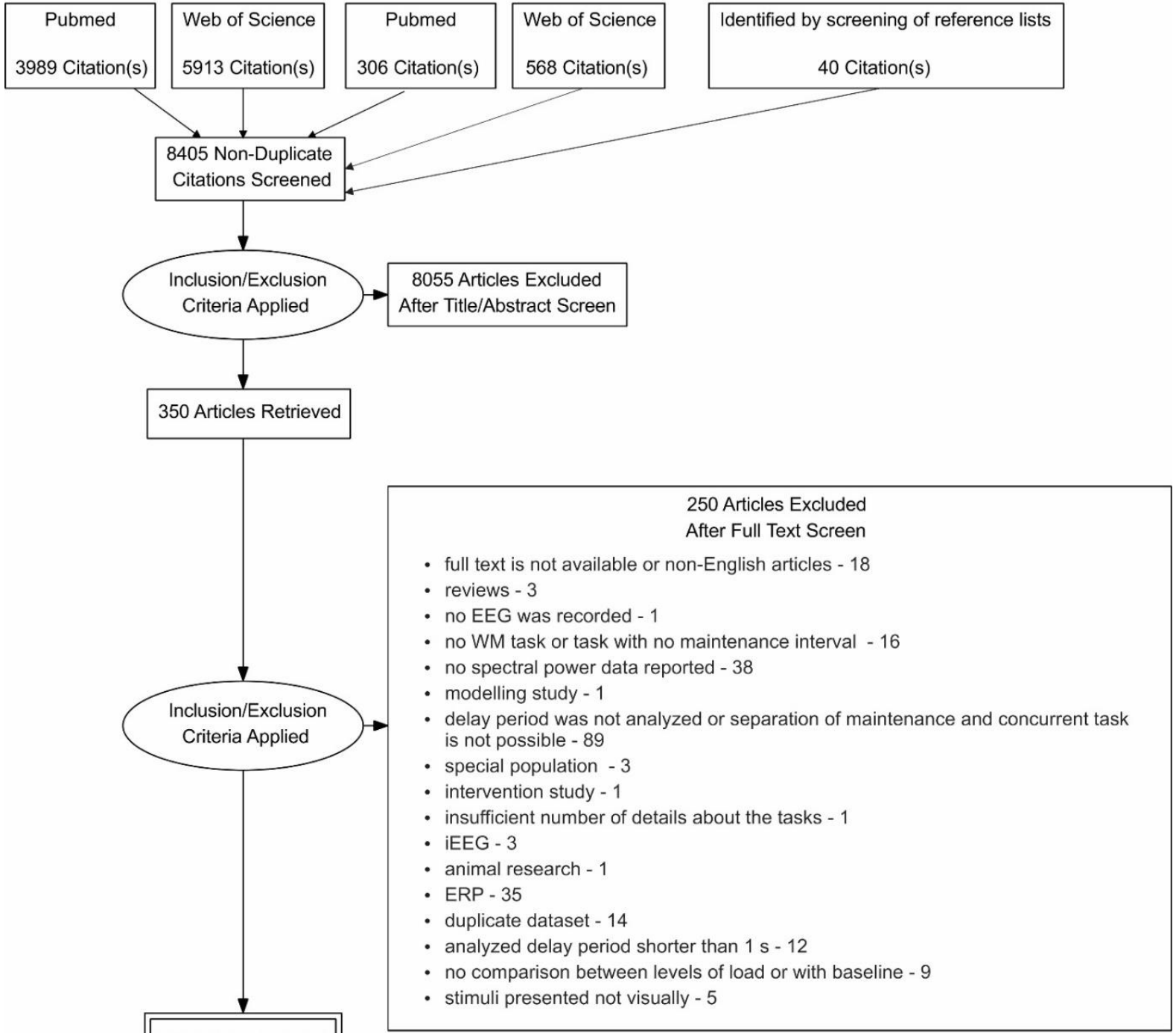

100 Articles Included

Figure 1 -Flow chart of the systematic review

Table 1 - Verbal WM studies included in the review

\begin{tabular}{|c|c|c|c|c|c|c|c|c|c|c|}
\hline Reference & $\mathbf{N}$ & 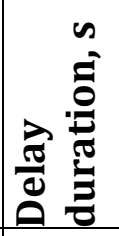 & Task & $\begin{array}{l}\text { Levels of } \\
\text { difficulty }\end{array}$ & 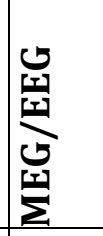 & تِّత & $\frac{\frac{\pi}{2}}{\frac{\pi}{\pi}}$ & تُّ & 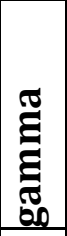 & 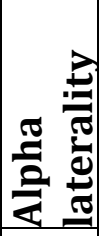 \\
\hline Altamura et al., 2010 & 20 & 1 & Sternberg (sim) & 1: 5 letters & MEG & - & - & $\uparrow$ & - & - \\
\hline Bashivan et al., 2014 & 15 & 3 & Sternberg (sim) & $\begin{array}{l}4: 2,4,6,8 \\
\text { letters }\end{array}$ & EEG & - & $\uparrow$ & 0 & - & $\mathrm{R}$ \\
\hline
\end{tabular}




\begin{tabular}{|c|c|c|c|c|c|c|c|c|c|c|}
\hline $\begin{array}{l}\text { Bonnefond \& Jensen, } \\
2012\end{array}$ & 18 & 1.1 & Sternberg (suc) & 1: 4 letters & MEG & - & $\uparrow *$ & - & - & - \\
\hline Brookes et al., 2011 & 8 & 8 & Sternberg (suc) & $\begin{array}{l}\text { 3: } 2,5,8 \\
\text { letters }\end{array}$ & MEG & $\uparrow$ & - & $\downarrow$ & $F$ & - \\
\hline $\begin{array}{l}\text { Gao, Sun, Yang, \& Gong, } \\
2018\end{array}$ & 26 & 3 & Sternberg (sim) & $\begin{array}{l}2: 4,6 \\
\text { letters }\end{array}$ & EEG & - & - & 0 & 0 & - \\
\hline \begin{tabular}{|l|} 
Griesmayr, Gruber, \\
Klimesch, \& Sauseng, \\
2010
\end{tabular} & 15 & 2.5 & DMTS & 1: 3 letters & EEG & $\uparrow$ & - & F & F & \\
\hline Harmony et al., 1996 & 10 & 2 & Sternberg (sim) & $\begin{array}{l}2: 3,5 \\
\text { digits }\end{array}$ & EEG & * & $\downarrow$ & - & - & - \\
\hline $\begin{array}{l}\text { Heinrichs-Graham \& } \\
\text { Wilson, } 2015\end{array}$ & 16 & 3 & Sternberg (sim) & 1: 6 letters & MEG & 0 & $\uparrow$ & $\uparrow$ & F & $\mathrm{R}$ \\
\hline $\begin{array}{l}\text { Hu et al., } 2019 \text { (study 1: } \\
\text { DMTS) }\end{array}$ & 23 & 5 & DMTS & $\begin{array}{l}3: 1,3,5 \\
\text { syllables }\end{array}$ & EEG & - & $\uparrow$ & - & - & $\mathrm{R}$ \\
\hline $\begin{array}{l}\text { Hu et al., } 2019 \text { (study 2: } \\
\text { Sternberg) }\end{array}$ & 20 & 3 & Sternberg (sim) & $\begin{array}{l}3: 1,3,5 \\
\text { digits }\end{array}$ & EEG & - & $\uparrow$ & - & F & $\mathrm{R}$ \\
\hline $\begin{array}{l}\text { Itthipuripat, Wessel, \& } \\
\text { Aron, } 2013\end{array}$ & 13 & 1.5 & $\begin{array}{l}\text { mod. Sternberg } \\
\text { (suc) }\end{array}$ & 1: 4 letters & EEG & $\uparrow$ & $\uparrow$ & $\downarrow$ & 0 & - \\
\hline Jensen \& Tesche, 2002 & 10 & 3 & Sternberg (suc) & $\begin{array}{l}4: 1,3,5,7 \\
\text { digits }\end{array}$ & MEG & $\uparrow$ & f & - & - & - \\
\hline Jensen et al., 2002 & 10 & 2.8 & Sternberg (sim) & $\begin{array}{l}3: 2,4,6 \\
\text { letters }\end{array}$ & EEG & $\uparrow$ & $\uparrow$ & - & - & $\mathrm{R}$ \\
\hline Khader et al., 2010 & 17 & $5-7$ & DMTS & 1: 6 letters & EEG & $\uparrow$ & $\uparrow$ & - & - & both \\
\hline Klimesch et al., 1999 & 14 & 8 & Sternberg (suc) & $\begin{array}{l}2: 5,10 \\
\text { letters and } \\
\text { digits }\end{array}$ & EEG & $\uparrow$ & $\uparrow$ & - & F & $\mathrm{R}$ \\
\hline $\begin{array}{l}\text { Klimesch, Schimke, \& } \\
\text { Pfurtscheller, } 1993\end{array}$ & 16 & 2 & Sternberg (sim) & $\begin{array}{l}2: 5,10 \\
\text { letters and } \\
\text { digits }\end{array}$ & EEG & - & $\uparrow$ & - & - & $\mathrm{R}$ \\
\hline Kottlow et al., 2015 & 22 & 3.5 & Sternberg (sim) & $\begin{array}{l}2: 2,5 \\
\text { letters }\end{array}$ & EEG & $\uparrow$ & $*$ & $*$ & - & $\mathrm{R}$ \\
\hline $\begin{array}{l}\text { Kustermann, Rockstroh, } \\
\text { Miller, \& Popov, } 2018 \\
\end{array}$ & 15 & 2 & Sternberg (sim) & $\begin{array}{l}3: 1,3,5 \\
\text { letters }\end{array}$ & MEG & 0 & $\uparrow$ & - & 0 & $\mathrm{R}$ \\
\hline Kwon et al., 2015 & 17 & 5 & simple span & $\begin{array}{l}2: 5,10 \\
\text { words }\end{array}$ & EEG & $\uparrow$ & $\downarrow$ & $F$ & - & F \\
\hline Meltzer et al., 2007 & 18 & 10.85 & Sternberg (sim) & $\begin{array}{l}3: 2,4,6 \\
\text { digits }\end{array}$ & EEG & 0 & 0 & - & F & both \\
\hline Michels et al., 2008 & 18 & 3 & Sternberg (sim) & $\begin{array}{l}3: 4,6,8 \\
\text { letters }\end{array}$ & EEG & $\uparrow$ & $*$ & - & F & $\mathrm{R}$ \\
\hline Michels et al., 2010 & 16 & 3.5 & Sternberg (sim) & $\begin{array}{l}2: 2,5 \\
\text { letters }\end{array}$ & EEG & $\uparrow$ & $\uparrow$ & $\uparrow$ & $\uparrow$ & $\mathrm{R}$ \\
\hline $\begin{array}{l}\text { Okuhata, Kusanagi, \& } \\
\text { Kobayashi, } 2013\end{array}$ & 10 & 3.2 & $\begin{array}{l}\text { Sternberg (sim, } \\
\text { suc) }\end{array}$ & $\begin{array}{l}2: 3,5 \\
\text { digits }\end{array}$ & EEG & - & $*$ & - & - & - \\
\hline
\end{tabular}




\begin{tabular}{|c|c|c|c|c|c|c|c|c|c|}
\hline $\begin{array}{l}\text { Onton, Delorme, \& } \\
\text { Makeig, } 2005\end{array}$ & 23 & $2-4$ & $\begin{array}{l}\text { mod. Sternberg } \\
\text { (suc) }\end{array}$ & $\begin{array}{l}3: 3,5,7 \\
\text { letters }\end{array}$ & EEG & $\uparrow$ & & $\uparrow$ & - \\
\hline Park, Min, et al., 2013 & 22 & 1.5 & Sternberg (suc) & $\begin{array}{l}3: 3,5,7 \\
\text { digits }\end{array}$ & EEG & $\uparrow$ & & c & \\
\hline $\begin{array}{l}\text { Pavlov \& Kotchoubey, } \\
2017\end{array}$ & 56 & 6.7 & $\begin{array}{l}\text { mod. Sternberg } \\
(\operatorname{sim})\end{array}$ & $\begin{array}{l}2: 5,7 \\
\text { letters }\end{array}$ & EEG & $\uparrow$ & * & $\uparrow$ & $\mathrm{R}$ \\
\hline Poch et al., 2010 & 11 & 1.2 & Sternberg (sim) & 1: 8 letters & MEG & $\uparrow$ & $\uparrow$ & $\uparrow$ & - \\
\hline $\begin{array}{l}\text { Proskovec, Heinrichs- } \\
\text { Graham, \& Wilson, 2019 }\end{array}$ & 26 & 3 & Sternberg (sim) & $\begin{array}{l}2: 4,6 \\
\text { letters }\end{array}$ & MEG & 0 & $\uparrow$ & & $\mathrm{R}$ \\
\hline $\begin{array}{l}\text { Schack \& Klimesch, } \\
2002\end{array}$ & 10 & 1.8 & Sternberg (suc) & $\begin{array}{l}4: 1,2,3,4 \\
\text { digits } \\
\text { presented } \\
\text { as words }\end{array}$ & EEG & $\uparrow$ & $\mid \uparrow$ & & - \\
\hline Scheeringa et al., 2009 & 20 & 7 & Sternberg (sim) & $\begin{array}{l}: 3,5,7 \\
\text { letters } \\
\end{array}$ & EEG & $\uparrow$ & $\uparrow$ & & $\mathrm{R}$ \\
\hline Stephane et al., 2010 & 19 & 2.05 & Sternberg (suc) & 1: 5 letters & MEG & 0 & $\downarrow$ & $\downarrow$ & both \\
\hline Wianda \& Ross, 2019 & 25 & 3 & $\begin{array}{l}\text { mod. Sternberg } \\
\text { (suc) }\end{array}$ & 1: 5 letters & MEG & - & $\uparrow$ & * & $\mathrm{R}$ \\
\hline $\begin{array}{l}\text { Wilson, Swain, \& } \\
\text { Ullsperger, } 1999\end{array}$ & 10 & 4 & simple span & $\begin{array}{l}5: 1,3,5,7, \\
8 \text { digits }\end{array}$ & EEG & $\uparrow$ & $\downarrow$ & & $\mathrm{R}$ \\
\hline $\begin{array}{l}\text { Xie, Feng, Xu, Bian, \& Li, } \\
2016\end{array}$ & 16 & 2 & Sternberg (suc) & $\begin{array}{l}4: 2,4,6,8 \\
\text { letters }\end{array}$ & EEG & - & $\uparrow$ & & - \\
\hline \begin{tabular}{|l|} 
Zakrzewska \& \\
Brzezicka, 2014
\end{tabular} & 69 & 2.5 & Sternberg (suc) & $\begin{array}{l}4: 2,3,4,5 \\
\text { letters }\end{array}$ & EEG & $\uparrow$ & & & \\
\hline
\end{tabular}

Notes: * complex results described in the main text of the systematic review, - no information available, $\uparrow$ increase, $\downarrow$ decrease, 0 no changes in the parameter, $\uparrow *$ the information acquired by personal communication. Levels of difficulty: Number of levels: number of items presented at each level of load. Task: suc - successive, sim simultaneous presentation of the stimuli, mod. Sternberg - modified Sternberg task. Alpha laterality: $\mathrm{R}$ - stronger alpha power changes in the right hemisphere; both - no clear difference between the hemispheres.

Table 2 - Visual WM studies included in the review

\begin{tabular}{|c|c|c|c|c|c|c|c|c|c|c|}
\hline Reference & $\mathbf{N}$ & 竎 & Content & $\begin{array}{l}\text { Levels } \\
\text { of } \\
\text { difficult } \\
y\end{array}$ & 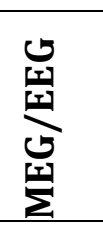 & 晃 & $\frac{\pi}{\frac{\pi}{\pi}}$ & هُّْ & 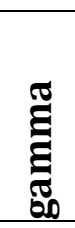 & $\frac{3}{\frac{3}{2}} \frac{3}{2}$ \\
\hline $\begin{array}{l}\text { Babiloni et al., } \\
2005\end{array}$ & 20 & $\begin{array}{l}3.5- \\
5.5\end{array}$ & $\begin{array}{l}\text { relative } \\
\text { height of } \\
\text { two bars }\end{array}$ & $1: 2$ & MEG & - & $\downarrow$ & - & - & $\begin{array}{l}\text { bot } \\
\text { h }\end{array}$ \\
\hline
\end{tabular}




\begin{tabular}{|c|c|c|c|c|c|c|c|c|c|c|}
\hline $\begin{array}{l}\text { Babiloni, } \\
\text { Babiloni, } \\
\text { Carducci, Cappa, } \\
\text { et al., } 2004\end{array}$ & 12 & $\begin{array}{l}3.5- \\
5.5\end{array}$ & $\begin{array}{l}\text { relative } \\
\text { height of } \\
\text { two bars }\end{array}$ & $1: 2$ & EEG & $\downarrow$ & $\downarrow$ & - & - & $\mathrm{R}$ \\
\hline $\begin{array}{l}\text { Bastiaansen, } \\
\text { Posthuma, Groot, } \\
\text { \& de Geus, } 2002\end{array}$ & 174 & $\begin{array}{l}1 \text { or } \\
4\end{array}$ & location & 1: 1 & EEG & $\downarrow$ & $\uparrow$ & - & - & $\mathrm{R}$ \\
\hline $\begin{array}{l}\text { Berger et al., } \\
2019\end{array}$ & 25 & 2 & location & $2: 1,4$ & EEG & $\uparrow$ & - & - & - & - \\
\hline $\begin{array}{l}\text { Blacker, Ikkai, } \\
\text { Lakshmanan, } \\
\text { Ewen, \& } \\
\text { Courtney, } 2016\end{array}$ & 18 & 2 & location & $1: 1$ & EEG & - & $\uparrow$ & - & - & $\begin{array}{l}\text { bot } \\
\text { h }\end{array}$ \\
\hline $\begin{array}{l}\text { Boonstra, Powell, } \\
\text { Mehrkanoon, \& } \\
\text { Breakspear, } 2013\end{array}$ & 8 & 6 & $\begin{array}{l}\text { object, } \\
\text { location }\end{array}$ & $3: 1,3,5$ & EEG & $\downarrow$ & $\downarrow$ & $\downarrow$ & - & $\begin{array}{l}\text { bot } \\
\text { h }\end{array}$ \\
\hline $\begin{array}{l}\text { Brookes et al., } \\
2012\end{array}$ & 10 & 6 & $\begin{array}{l}\text { shape } \\
\text { (serial } \\
\text { order) }\end{array}$ & $1: 2$ & MEG & 0 & $\downarrow$ & $\downarrow$ & 0 & - \\
\hline $\begin{array}{l}\text { Busch \& } \\
\text { Herrmann, } 2003\end{array}$ & 16 & 3 & $\begin{array}{l}\text { shape, } \\
\text { color, } \\
\text { texture }\end{array}$ & $3: 1,3,6$ & EEG & - & $\uparrow$ & - & - & - \\
\hline $\begin{array}{l}\text { Crespo-Garcia et } \\
\text { al., } 2013\end{array}$ & 29 & $2.5-5$ & location & $2: 3,5$ & EEG & - & $\uparrow$ & - & - & $\begin{array}{l}\text { bot } \\
\mathrm{h}\end{array}$ \\
\hline $\begin{array}{l}\text { Daume et al., } \\
2017\end{array}$ & 29 & 3 & object & $1: 1$ & MEG & 0 & $*$ & $\uparrow$ & $\uparrow$ & $\begin{array}{l}\text { bot } \\
\text { h }\end{array}$ \\
\hline $\begin{array}{l}\text { Daume, Gruber, } \\
\text { Engel, \& Friese, } \\
2017\end{array}$ & 27 & 3 & object & $1: 1$ & MEG & 0 & $*$ & $\uparrow$ & $\uparrow$ & - \\
\hline $\begin{array}{l}\text { de Vries, Driel, \& } \\
\text { Olivers, } 2017\end{array}$ & 20 & 1,8 & color & $2: 1,2$ & EEG & - & $\downarrow$ & - & - & $\begin{array}{l}\text { bot } \\
\mathrm{h}\end{array}$ \\
\hline $\begin{array}{l}\text { de Vries, Savran, } \\
\text { van Driel, \& } \\
\text { Olivers, } 2019 \\
\end{array}$ & 22 & 1.4 & color & $1: 1$ & EEG & $\downarrow$ & $\downarrow$ & - & - & $\begin{array}{l}\text { bot } \\
\text { h }\end{array}$ \\
\hline $\begin{array}{l}\text { Ellmore, } \mathrm{Ng}, \& \\
\text { Reichert, } 2017\end{array}$ & 15 & 6 & $\begin{array}{l}\text { image } \\
\text { (serial } \\
\text { order) }\end{array}$ & $1: 2$ & EEG & 0 & $\uparrow$ & - & - & $\mathrm{R}$ \\
\hline $\begin{array}{l}\text { Erickson et al., } \\
2019\end{array}$ & 60 & 2 & $\begin{array}{l}\text { color, } \\
\text { location }\end{array}$ & $3: 2,4,6$ & EEG & - & $\downarrow$ & $\downarrow$ & - & $\begin{array}{l}\text { bot } \\
\text { h }\end{array}$ \\
\hline $\begin{array}{l}\text { Eschmann, } \\
\text { Bader, \& } \\
\text { Mecklinger, } 2018\end{array}$ & 27 & 2 & location & $2: 1,4$ & EEG & $\uparrow$ & - & - & - & - \\
\hline $\begin{array}{l}\text { Fukuda, Mance, \& } \\
\text { Vogel, } 2015\end{array}$ & 33 & $1-4$ & $\begin{array}{l}\text { color, } \\
\text { location }\end{array}$ & $\begin{array}{l}6: 1,2,3 \\
4,6,8\end{array}$ & EEG & - & $\downarrow$ & - & - & - \\
\hline $\begin{array}{l}\text { Grimault et al., } \\
2009\end{array}$ & 27 & 1.2 & $\begin{array}{l}\text { color, } \\
\text { location }\end{array}$ & $2: 2,4$ & MEG & - & $\uparrow$ & - & - & - \\
\hline $\begin{array}{l}\text { Heinz \& Johnson, } \\
2017\end{array}$ & 18 & 1.4 & shape & $2: 2,4$ & EEG & - & $\uparrow$ & - & - & - \\
\hline
\end{tabular}




\begin{tabular}{|c|c|c|c|c|c|c|c|c|c|c|}
\hline $\begin{array}{l}\text { Herrmann, } \\
\text { Senkowski, \& } \\
\text { Rottger, } 2004 \\
\end{array}$ & 22 & $3-4$ & angle & $1: 1$ & EEG & - & $\uparrow$ & - & - & $\begin{array}{l}\text { bot } \\
\text { h }\end{array}$ \\
\hline $\begin{array}{l}\text { Honkanen, } \\
\text { Rouhinen, Wang, } \\
\text { Palva, \& Palva, } \\
2015\end{array}$ & 13 & 2.05 & shape & $2: 2,4$ & $\begin{array}{l}\text { MEG } \\
\text { /EEG } \\
\text { conc } \\
\text { urre } \\
\text { nt }\end{array}$ & 0 & $\downarrow$ & $\uparrow$ & $\uparrow$ & - \\
\hline $\begin{array}{l}\text { Ichihara-Takeda } \\
\text { et al., } 2015\end{array}$ & 10 & 5 & location & $1: 1$ & MEG & - & $\uparrow$ & - & - & $\mathrm{R}$ \\
\hline Ikkai et al., 2014 & 18 & 2 & location & $1: 2$ & EEG & - & $\uparrow$ & - & - & - \\
\hline $\begin{array}{l}\text { Johnson, } \\
\text { Sutterer, } \\
\text { Acheson, Lewis- } \\
\text { Peacock, \& } \\
\text { Postle, } 2011\end{array}$ & 12 & 3 & $\begin{array}{l}\text { shape, } \\
\text { location }\end{array}$ & $1: 4$ & EEG & - & $\uparrow$ & - & - & $\mathrm{R}$ \\
\hline $\begin{array}{l}\text { Jokisch \& Jensen, } \\
2007\end{array}$ & 10 & 3 & face & $1: 1$ & MEG & - & $\uparrow$ & - & $\uparrow$ & $\begin{array}{l}\text { bot } \\
\mathrm{h}\end{array}$ \\
\hline $\begin{array}{l}\text { Kaplan et al., } \\
2016\end{array}$ & 16 & 20 & $\begin{array}{l}\text { location, } \\
\text { object } \\
\text { (serial } \\
\text { order) }\end{array}$ & $1: 5$ & MEG & $\uparrow$ & - & - & - & - \\
\hline $\begin{array}{l}\text { Kawasaki \& } \\
\text { Yamaguchi, } 2012\end{array}$ & 19 & 2 & $\begin{array}{l}\text { shape, } \\
\text { location }\end{array}$ & $3: 2,4,6$ & EEG & $\uparrow$ & $\downarrow$ & - & - & - \\
\hline $\begin{array}{l}\text { Kawasaki \& } \\
\text { Yamaguchi, } 2013\end{array}$ & 14 & 2 & $\begin{array}{l}\text { color, } \\
\text { location }\end{array}$ & $2: 3,6$ & EEG & $\uparrow$ & $\downarrow$ & - & - & - \\
\hline $\begin{array}{l}\text { Khader, Jost, } \\
\text { Ranganath, \& } \\
\text { Rosler, } 2010 \\
\end{array}$ & 17 & $5-7$ & object & $1: 1$ & EEG & $\uparrow$ & $\uparrow$ & - & - & $\begin{array}{l}\text { bot } \\
\text { h }\end{array}$ \\
\hline $\begin{array}{l}\text { Kulashekhar, } \\
\text { Pekkola, Palva, \& } \\
\text { Palva, } 2016\end{array}$ & 13 & $\begin{array}{l}1.1- \\
1.3\end{array}$ & color & $1: 1$ & MEG & $\downarrow$ & $\uparrow$ & $\downarrow$ & 0 & - \\
\hline $\begin{array}{l}\text { Manza, Hau, \& } \\
\text { Leung, } 2014\end{array}$ & 31 & 2 & $\begin{array}{l}\text { color, } \\
\text { location }\end{array}$ & $3: 1,3,6$ & EEG & - & $\uparrow$ & - & - & $\begin{array}{l}\text { bot } \\
\mathrm{h}\end{array}$ \\
\hline $\begin{array}{l}\text { Mapelli \& Ozkurt, } \\
2019\end{array}$ & 28 & $1-1.5$ & object & $1: 4$ & EEG & - & $\uparrow$ & - & - & $\mathrm{R}$ \\
\hline $\begin{array}{l}\text { Maurer et al., } \\
2015\end{array}$ & 24 & 3.5 & shape & $2: 2,4$ & EEG & $\uparrow$ & $*$ & - & - & $\mathrm{R}$ \\
\hline $\begin{array}{l}\text { Medendorp et al., } \\
2007\end{array}$ & 8 & 2,4 & $\begin{array}{l}\text { location } \\
\text { (serial } \\
\text { order) } \\
\end{array}$ & $2: 1,2$ & MEG & - & $\downarrow$ & $\downarrow$ & - & - \\
\hline $\begin{array}{l}\text { Moran et al., } \\
2010\end{array}$ & 14 & 1.2 & $\begin{array}{l}\text { color, } \\
\text { location }\end{array}$ & $\begin{array}{l}4: 2,3,4, \\
6\end{array}$ & MEG & $\uparrow$ & $\uparrow$ & - & - & - \\
\hline $\begin{array}{l}\text { Morgan et al., } \\
2011\end{array}$ & 16 & 2 & color, angle & $2: 1,2$ & $\mathrm{MEG}$ & - & - & - & $\uparrow$ & - \\
\hline $\begin{array}{l}\text { Nenert, } \\
\text { Viswanathan, }\end{array}$ & 16 & $1-3$ & $\begin{array}{l}\text { location, } \\
\text { orientation }\end{array}$ & $3: 2,4,6$ & EEG & - & $\uparrow$ & - & - & $\begin{array}{l}\text { bot } \\
\text { h }\end{array}$ \\
\hline
\end{tabular}




\begin{tabular}{|c|c|c|c|c|c|c|c|c|c|c|}
\hline $\begin{array}{l}\text { Dubuc, \& } \\
\text { Visscher, } 2012\end{array}$ & & & & & & & & & & \\
\hline $\begin{array}{l}\text { Okada \& } \\
\text { Salenius, } 1998\end{array}$ & 4 & 2.8 & location & $1: 4$ & MEG & - & 0 & - & - & - \\
\hline $\begin{array}{l}\text { Olsen, Rondina, } \\
\text { Riggs, Meltzer, \& } \\
\text { Ryan, } 2013\end{array}$ & 12 & 2 & $\begin{array}{l}\text { object, } \\
\text { location }\end{array}$ & $1: 3$ & MEG & $\uparrow$ & - & - & - & - \\
\hline $\begin{array}{l}\text { Pahor \& } \\
\text { Jausovec, } 2017\end{array}$ & 60 & 1 & $\begin{array}{l}\text { color, } \\
\text { location }\end{array}$ & $3: 4,6,8$ & EEG & - & $\downarrow$ & - & $\downarrow$ & $\mathrm{R}$ \\
\hline Park et al., 2011 & 11 & $\begin{array}{l}2.5- \\
3.5\end{array}$ & location & $1: 2$ & MEG & 0 & $\uparrow$ & $*$ & $*$ & $\begin{array}{l}\text { bot } \\
\text { h }\end{array}$ \\
\hline $\begin{array}{l}\text { Poch, Campo, \& } \\
\text { Barnes, } 2014\end{array}$ & 17 & 1 & $\begin{array}{l}\text { orientation } \\
\text {, location }\end{array}$ & $2: 1,2$ & MEG & - & $\uparrow$ & - & 0 & - \\
\hline $\begin{array}{l}\text { Poch, Valdivia, } \\
\text { Capilla, Hinojosa, } \\
\text { \& Campo, } 2018\end{array}$ & 36 & 1 & $\begin{array}{l}\text { orientation } \\
\text {, location }\end{array}$ & $3: 2,3,4$ & EEG & - & $\downarrow$ & - & - & - \\
\hline $\begin{array}{l}\text { Proskovec, } \\
\text { Wiesman et al, } \\
2018,2019 \\
\text { combined }\end{array}$ & 22 & 2.5 & location & $2: 2,4$ & MEG & $\downarrow$ & $\downarrow$ & $\downarrow$ & 0 & - \\
\hline $\begin{array}{l}\text { Rawle, Miall, \& } \\
\text { Praamstra, } 2012\end{array}$ & 20 & 1 & $\begin{array}{l}\text { color, } \\
\text { location }\end{array}$ & $3: 1,2,4$ & EEG & $\downarrow$ & $\downarrow$ & $\downarrow$ & 0 & - \\
\hline $\begin{array}{l}\text { Román-López et } \\
\text { al., } 2019\end{array}$ & 26 & 2,5 & $\begin{array}{l}\text { color, } \\
\text { shape }\end{array}$ & $1: 2$ & EEG & $\uparrow$ & $\uparrow$ & $\uparrow$ & - & - \\
\hline $\begin{array}{l}\text { Rominger et al., } \\
2019\end{array}$ & 52 & 3 & shape & $1: 4$ & EEG & - & $\uparrow$ & - & - & $\mathrm{R}$ \\
\hline Roux et al., 2012 & 25 & 1.2 & location & $2: 3,6$ & MEG & 0 & $\uparrow$ & $\uparrow$ & $\uparrow$ & - \\
\hline $\begin{array}{l}\text { Sauseng et al., } \\
2005\end{array}$ & 23 & 2.5 & location & $1: 3$ & EEG & - & $\uparrow$ & - & - & $\begin{array}{l}\text { bot } \\
\text { h }\end{array}$ \\
\hline $\begin{array}{l}\text { Schroeder, Ball, } \\
\text { \& Busch, } 2018\end{array}$ & 30 & 1.2 & orientation & $2: 1,2$ & EEG & - & $\downarrow$ & - & - & - \\
\hline $\begin{array}{l}\text { Seemuller, } \\
\text { Muller, \& Rosler, } \\
2012\end{array}$ & 17 & 1 & angle & $1: 1$ & EEG & 0 & $\downarrow$ & $\downarrow$ & - & $\begin{array}{l}\text { bot } \\
\text { h }\end{array}$ \\
\hline $\begin{array}{l}\text { Smyrnis et al., } \\
2014\end{array}$ & 10 & $\begin{array}{l}3.5- \\
4.5\end{array}$ & location & $1: 1$ & EEG & - & - & $\downarrow$ & $\downarrow$ & - \\
\hline $\begin{array}{l}\text { Spitzer \& } \\
\text { Blankenburg, } \\
2012\end{array}$ & 28 & 3 & $\begin{array}{l}\text { light } \\
\text { blinking } \\
\text { frequency }\end{array}$ & $1: 1$ & EEG & 0 & $\uparrow$ & - & - & $\begin{array}{l}\text { bot } \\
\text { h }\end{array}$ \\
\hline $\begin{array}{l}\text { Spitzer, Fleck, \& } \\
\text { Blankenburg, } \\
2014\end{array}$ & 24 & 3 & quantity & $\begin{array}{l}6: 3,4,5, \\
6,7,8\end{array}$ & EEG & - & $\uparrow$ & $\uparrow$ & - & $\begin{array}{l}\text { bot } \\
\text { h }\end{array}$ \\
\hline $\begin{array}{l}\text { Takase, Boasen, } \\
\text { \& Yokosawa, } \\
2019\end{array}$ & 29 & 1.5 & $\begin{array}{l}\text { orientation } \\
\text { (serial } \\
\text { order) }\end{array}$ & $1: 7$ & MEG & $\uparrow$ & $\uparrow$ & - & - & - \\
\hline $\begin{array}{l}\text { Tallon-Baudry, } \\
\text { Kreiter, \& } \\
\text { Bertrand, } 1999\end{array}$ & 13 & $\begin{array}{l}0.8- \\
1.6\end{array}$ & location & $1: 1$ & EEG & - & - & $\uparrow$ & $*$ & - \\
\hline
\end{tabular}




\begin{tabular}{|c|c|c|c|c|c|c|c|c|c|c|}
\hline $\begin{array}{l}\text { Trubutschek et } \\
\text { al., } 2017\end{array}$ & 13 & $2.5-4$ & location & $1: 1$ & MEG & - & $\uparrow$ & $\downarrow$ & - & - \\
\hline $\begin{array}{l}\text { Trubutschek et } \\
\text { al., } 2019\end{array}$ & 30 & $1.5-3$ & location & $1: 1$ & MEG & - & - & $\downarrow$ & - & - \\
\hline $\begin{array}{l}\text { Tuladhar et al., } \\
2007\end{array}$ & 5 & 2.7 & $\begin{array}{l}\text { face (serial } \\
\text { order) }\end{array}$ & $\begin{array}{l}4: 1,2,3, \\
4\end{array}$ & MEG & - & $\uparrow$ & - & - & - \\
\hline $\begin{array}{l}\text { van Dijk et al., } \\
2010\end{array}$ & 18 & 1.5 & location & $1: 1$ & MEG & - & 0 & - & - & - \\
\hline $\begin{array}{l}\text { van Ede, Jensen, } \\
\text { \& Maris, } 2017\end{array}$ & 16 & 4 & $\begin{array}{l}\text { location } \\
\text { (serial } \\
\text { order) } \\
\end{array}$ & $2: 2,4$ & MEG & $\uparrow$ & $\downarrow$ & $\downarrow$ & $\uparrow$ & $\begin{array}{l}\text { bot } \\
h\end{array}$ \\
\hline $\begin{array}{l}\text { Vandenbroucke, } \\
\text { Sligte, de Vries, } \\
\text { Cohen, \& Lamme, } \\
2015\end{array}$ & 25 & 1 & $\begin{array}{l}\text { orientation } \\
\text {, location }\end{array}$ & $\begin{array}{l}4: 2,4,6, \\
8\end{array}$ & EEG & 0 & $\downarrow$ & - & - & - \\
\hline $\begin{array}{l}\text { Vissers, van } \\
\text { Driel, \& Slagter, } \\
2016\end{array}$ & 31 & 1 & color & $2: 2,4$ & EEG & $\uparrow$ & $\downarrow$ & $\uparrow$ & - & - \\
\hline Yin et al., 2012 & 12 & 1 & shape & $1: 3$ & EEG & $\downarrow$ & $\uparrow$ & - & - & - \\
\hline $\begin{array}{l}\text { Zhang, Zhao, Bai, } \\
\text { \& Tian, } 2016\end{array}$ & 16 & 3 & $\begin{array}{l}\text { object } \\
\text { (serial } \\
\text { order) }\end{array}$ & $\begin{array}{l}6: 1,2,3 \\
4,5,6\end{array}$ & EEG & $\uparrow$ & - & - & 0 & - \\
\hline
\end{tabular}

Notes: * complex results described in the main text of the systematic review, - no information available, $\uparrow$ increase, $\downarrow$ decrease, 0 no changes in the parameter. Levels of difficulty: Number of levels: number of items presented at each level of load. Alpha laterality: $\mathrm{R}$ - stronger alpha power changes in the right hemisphere; both - no clear difference between the hemispheres. Content: type of content presented for encoding. Serial order - the items presented in the way the rehearsal in a sequence is likely to occur.

\subsection{General results}

Of the 100 selected studies, the number of verbal and visual WM studies was 35 and 65 respectively (see Table 1 and Table 2 respectively). Among verbal studies, ten studies employed MEG and 25 EEG. Among visual studies, there were twenty-four MEG studies, 40 EEG studies, and one study with concurrent EEG/MEG recording.

The number of participants did not significantly differ between the studies carried out in verbal $($ mean $\pm \mathrm{SD}=19.3 \pm 12$, median $=17)$ and visual modalities (mean $\pm \mathrm{SD}=23.3 \pm$ 21.9 , median $=18)(\mathrm{t}(98)=1.02, \mathrm{p}=0.311$; see Figure 2 for the distribution $)$. 
In verbal studies, the duration of the delay period varied in a range of 1-10.85 s, in the visual modality from 1 to $20 \mathrm{~s}$. Some studies used variable delay duration. In these cases, we included the longest intervals in the analysis. To account for outliers, the median instead of the mean value was used as a central tendency measure. The median duration of the delay period across all 100 studies was $2.8 \mathrm{~s}$, and the difference between the modalities (verbal: $3 \mathrm{~s}$; visual: $2.5 \mathrm{~s}$ ) did not attain significance $(U=1394, \mathrm{p}=0.063$; see Figure 2).

Fifty-eight of the 100 studies (58\%) varied set-size and consequently the WM load. The proportion of the verbal WM studies exploring more than one level of load (74\%, 26/35) was larger in comparison with visual modality $(48 \%, 31 / 65)\left(\chi^{2}=6.56, p=0.01\right)$. Verbal experiments never used a single item to encode without additional levels of load $(0 \%$, $0 / 35)$. The proportion was significantly smaller than in visual modality $(26 \%, 17 / 65)\left(\chi^{2}\right.$ $=11, \mathrm{p}<0.001)$.

Figure 2 depicts the distribution of the levels of load in the two WM domains. As can be seen in the figure, load variation starting from one item is quite typical in visual $(25 \%$, $30 / 118)$ but significantly less common in verbal $(7 \%, 6 / 84)$ domain $\mathrm{WM}$ research $\left(\chi^{2}=\right.$ $11.2, \mathrm{p}<0.001)$. 


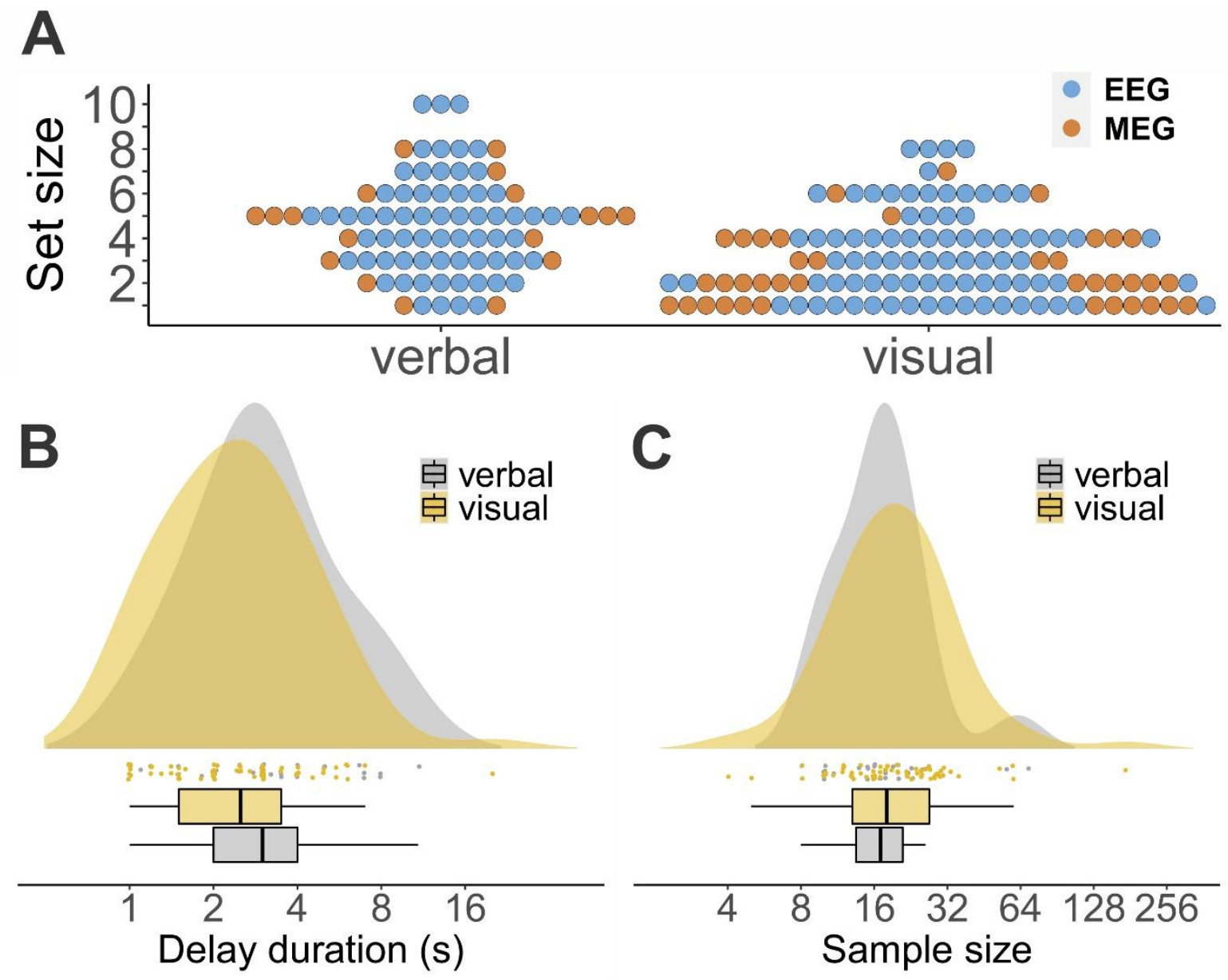

Figure 2 - (A) Distribution of set-sizes by WM modality. Each dot represents one level of load in a study. Note that there are many more dots than studies because one study could use several levels of load. (B) Distribution of the delay period durations. (C) Distribution of sample sizes. Raincloud plots (Allen, Poggiali, Whitaker, Marshall, \& Kievit, 2018) were used to visualize the distributions in $\mathrm{B}$ and $\mathrm{C}$ panels. Note the logarithmic scale in panels B and C.

\subsection{WM tasks}

$71 \%$ of verbal WM studies (25/35) used the classic version of the Sternberg task (Sternberg, 1966). In this task, the temporal subprocesses in WM such as encoding, maintenance, and retrieval are separated. In the classic version of the task at the encoding phase one or several items are presented either simultaneously or in a succession, which is followed by a delay period (maintenance interval). After the delay, a single-item probe 
is presented at the retrieval stage where participants have to decide whether the probe matches any of the items in the encoded memory set. The Sternberg task shares the advantage of temporal separation of subprocesses with the delayed matching-to-sample (DMTS) paradigm. In verbal DMTS, however, (1) only simultaneous presentation of items is possible at the encoding phase, and (2) all the items are probed simultaneously at the retrieval stage. In three studies the DMTS paradigm was used. Two other studies employed simple span paradigm with free recall.

Five other studies used modified Sternberg paradigms. The modifications included: instead of encoding all letters the participants had to memorize only the marked ones and ignored the others (Onton, Delorme, \& Makeig, 2005); the task was to memorize only the letters presented in the previously cued hemifield (Kustermann, Rockstroh, Miller, \& Popov, 2018), in a fashion similar to the lateralized change detection paradigm (Vogel \& Machizawa, 2004); at the retrieval phase the probe was replaced by the task to reproduce the sequence of four items by clicking on the presented items in the right order (Itthipuripat, Wessel, \& Aron, 2013); a similar manipulation with the probe was done in another study where the probe consisted of two items: a letter and a digit representing the serial number of the presented letter, and the participants had to indicate whether the letter was on the presented serial position in the encoded letters string (Pavlov \& Kotchoubey, 2017); in one study the probe was a pair of letters, each of them was presented at the encoding but the order of the letters was either correct or reversed (Wianda \& Ross, 2019).

Letters (24/35), digits (6/34), words (2/35), a combination of digits and letters $(2 / 35)$, and syllables $(1 / 35)$ were used in verbal WM tasks.

Visual WM tasks were much more diverse. In an attempt to systematically categorize the tasks, we used a two-factor model. A typical task involves the presentation of memory items sequentially or simultaneously, followed by the delay period and a probe. An important distinction between the tasks can be made by (1) the type of content for memory maintenance (e.g., location, shape, color, etc of the stimuli or images or faces to memorize) and (2) relevance of the presentation order to solve the task. For example, a typical change detection task (Luck \& Vogel, 1997) requires to memorize the color and location of squares occupying all visual field. The squares are presented simultaneously making the memory content essentially a single complex item, not a sequence of 
independent items. In the opposite case, a sequence of complex images (e.g., everyday objects) more likely to be stored as a sequence, not as one complex object.

In 12/65 studies the stimuli were presented sequentially but in three of them there was no need to maintain the order of presentation along with the identity of stimuli (see Table 2). As an example, Olsen et al. (2013) presented simple objects sequentially at different non-overlapping positions on the screen. Although the objects were presented in a succession, they may easily be stored as a whole. Thus, the majority $(86 \%, 56 / 65)$ of visual WM studies required participants to maintain only the content.

The following content was used in the visual WM tasks: complex objects such as images, recognizable everyday objects (9), faces (2), shapes (geometric shapes or symbols) (10), location (of dots, shapes, or objects) (39), color (16), orientation (7), texture (1), angle (2), frequency of a blinking light (1) and the number of the blinks (1), the relative height of two bars (2). The sum of the above numbers is larger than 65 because some studies used items with more than one feature.

\subsection{Theta}

In 25 (18 EEG / 7 MEG) of 35 verbal WM studies, theta rhythm was featured in the results or depicted in figures (see Table 1). The theta has never been found to decrease in EEG verbal WM tasks with an exception of one study (Harmony et al., 1996). The study reported a decrease of theta compared with baseline, but only in a low load condition (memorizing 3 digits). One EEG study reported null findings on the group level (Meltzer, Negishi, Mayes, \& Constable, 2007). All the other EEG studies reported an increase of theta activity during the delay. Another common finding frequently reported in the EEG literature is a stepwise increase of theta activity with load. The review identified 15 studies using the tasks with more than one level of WM load. The effect of stepwise increase of theta was found in ten out of the 15 studies. In addition to the abovementioned study of Harmony et al. (1996), in one study the stepwise increase of theta activity was observed only in high-performance participants (Pavlov \& Kotchoubey, 2017). No observable and/or statistically significant stepwise increase was found in three studies (Kwon et al., 2015; Meltzer et al., 2007; Schack \& Klimesch, 2002). As we can see, EEG verbal WM research strongly supports the hypothesis of the involvement of theta oscillations in WM maintenance processes. 
The picture is less clear when MEG data are taken into account. There is only one MEG study where stepwise theta increase with WM load was demonstrated (Jensen \& Tesche, 2002). Another study found theta increase from 2- to 5-letters conditions but no further increase in the 8-letters condition (Brookes et al., 2011). Poch et al. (2010) reported an increase of theta in comparison with baseline. Three studies did not report any sustained increase of theta during the delay period (Kustermann et al., 2018; Proskovec, HeinrichsGraham, \& Wilson, 2019; Stephane et al., 2010).

Finally, one MEG study did not find any theta change either during encoding or during the delay period (Heinrichs-Graham \& Wilson, 2015). These authors explicitly noticed the discrepancy between their findings and the results of previous MEG and EEG studies. They explained the inconsistency by the difference between the simultaneous presentation of stimuli in their study and the successive presentation in those MEG studies where the effect was found (Brookes et al., 2011; Jensen \& Tesche, 2002). However, the hypothesis is not supported by our data. The increase of theta with load was reproducible in both simultaneous (7/11 studies) and successive (8/9 studies) varieties of the Sternberg paradigm $\left(\chi^{2}=1.68, p=0.19\right)$. Inclusion of the studies using the simple span (successive presentation, 2 studies) and DMTS (simultaneous presentation, 2 studies) paradigms did not change the result (9/13 vs 10/11 studies in the successive and simultaneous categories, respectively, $\chi^{2}=1.69, \mathrm{p}=0.19$ ). 


\section{Theta}

verbal

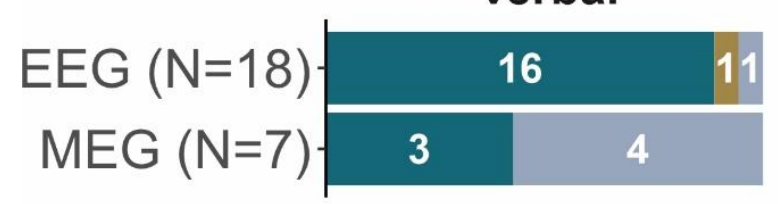

\begin{tabular}{c|ccc} 
& \multicolumn{3}{|c}{ visual } \\
\cline { 2 - 4 } $\operatorname{EEG}(\mathrm{N}=19)$ & $\mathbf{9}$ & $\mathbf{4}$ & $\mathbf{6}$ \\
\cline { 2 - 4 } $\operatorname{MEG}(\mathrm{N}=13)$ & $\mathbf{5}$ & 6 & $\mathbf{2}$
\end{tabular}

\begin{tabular}{l|l|l}
19 & 5 & verbal vs visual
\end{tabular}

14

$x^{2}=7.12, p=0.008$

\begin{tabular}{l|l}
25 & 11 \\
EEG vs MEG
\end{tabular}

8

\section{Alpha}

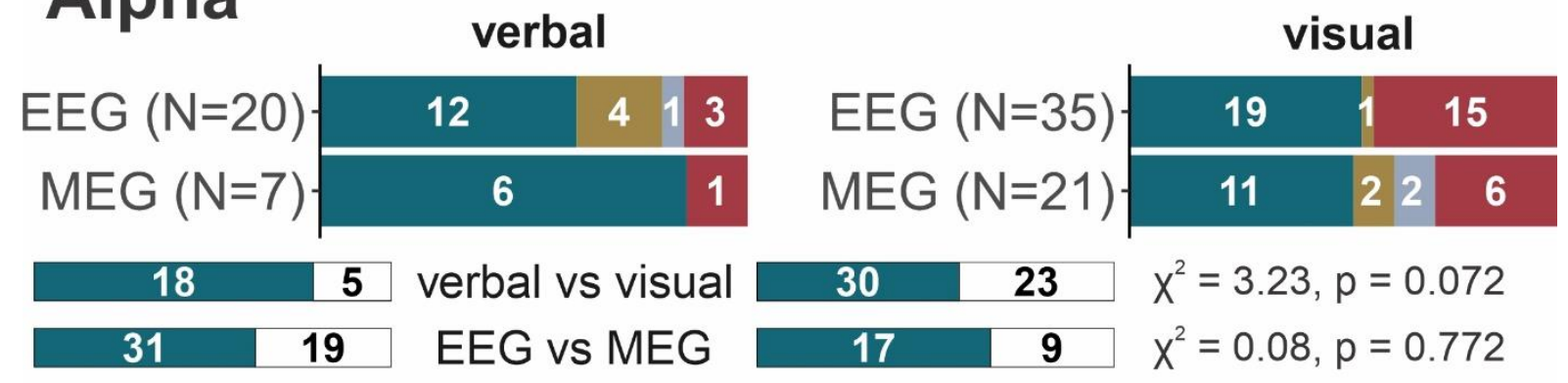

\section{Beta}

verbal

\begin{tabular}{|c|c|c|c|c|}
\hline $\operatorname{EEG}(\mathrm{N}=9)$ & 3 & 1 & 3 & 2 \\
\hline $\operatorname{MEG}(\mathrm{N}=6)$ & 3 & & 1 & 2 \\
\hline
\end{tabular}

\begin{tabular}{l|l|l|l}
6 & 7 & verbal vs visual
\end{tabular} EEG vs MEG

\begin{tabular}{|c|c|c|c|}
\hline & \multicolumn{3}{|c|}{ visual } \\
\hline EEG $(\mathrm{N}=9)$ & 4 & & 5 \\
\hline $\operatorname{MEG}(\mathrm{N}=12)$ & 4 & 1 & 7 \\
\hline 8 & $x^{2}=0$. & & 0.727 \\
\hline 7 & $x^{2}=0$ & .02 , & $=0.881$ \\
\hline
\end{tabular}

visual

\section{Gamma}

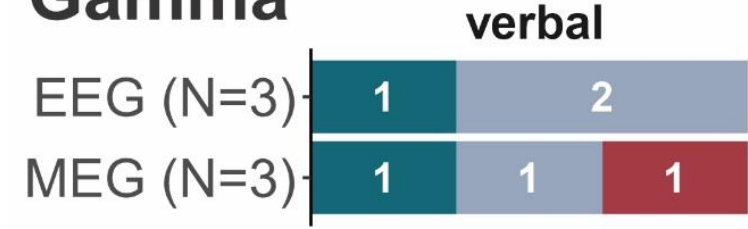

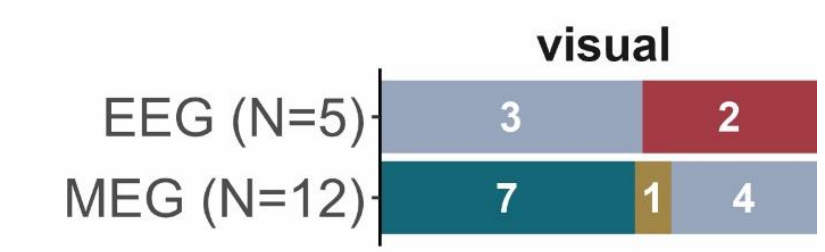

$x^{2}=0.19, p=0.658$ $X^{2}=4.19, p=0.040$

\begin{tabular}{|c|c|}
\hline 7 & 9 \\
\hline 8 & 6 \\
\hline
\end{tabular}

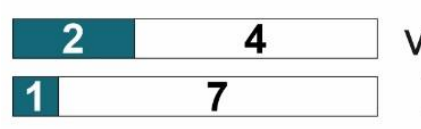

increase verbal vs visual EEG vs MEG
$12 \quad x^{2}=4.6, p=0.032$ 
Elucidating the role of theta rhythm in the maintenance of WM, Hsieh et al. (2011) argued that theta is important for the maintenance of temporal order and less relevant to the storage function. In the classic Sternberg task, only one item is probed. It means that maintaining the order of the presented items is irrelevant to the task. However, a piece of evidence is provided by a MEG study that compared two conditions: (1) memorizing only content and (2) memorizing the content as well as the location of the presented stimuli (Poch et al., 2010). In this study, the information about the order can be seen as the spatial dimension added to the verbal content. The authors found a stronger theta increase in the verbal-spatial condition in comparison with the verbal condition.

It appears to be difficult to design a task that could provide sufficient evidence for or against this hypothesis in the verbal domain. Moreover, even presented simultaneously verbal content is rehearsed in a sequence. It can be less of a problem for the visual WM domain. Moreover, in a visual Sternberg paradigm using unpronounceable shapes, theta effects were still observable (Maurer et al., 2015). Given the obvious limitation of verbal WM studies in the context of this hypothesis, it can be beneficial to broaden the scope of this part of the review to the visual WM studies.

19/40 EEG and MEG 13/25 visual WM studies featured theta in the results. Among the 19+13=32 studies, nine EEG and five MEG studies reported an increase in theta activity during the delay, 6 EEG and 2 MEG studies found a decrease of theta, and 4 EEG and 6 MEG studies reported null effects. Because, as compared with verbal WM studies, a demonstration of a decrease in theta power appears unexpected, we looked at the corresponding set of studies more closely.

We first hypothesized that this result may be explained by a broadband power suppression of alpha also occupying neighboring frequencies. Although, in five studies the theta decrease was indeed accompanied by a similar alpha decrease; in the other three studies, alpha increased with load. Thus, the hypothesis was not supported by the data (5/8 vs $\left.3 / 8: \chi^{2}=1, p=0.317\right)$.

One of the eight studies reported theta decrease was the study by Boonstra et al. (2013). However, the data shown in the bottom panel of the first figure in the study (see our Figure 4 below) challenge the conclusion of theta suppression during the delay. One can notice that the 4-8 Hz frequency band designated by the authors as theta largely overlaps 
with alpha and shares its behavior. Taking into account this observation, sustained theta activity in this work was in fact absent.

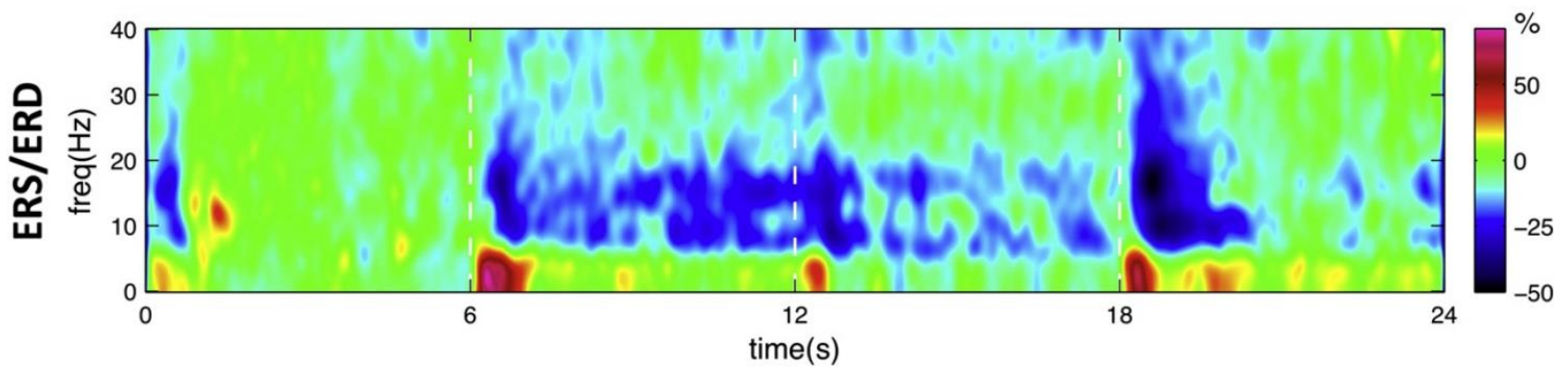

Figure 4 - Time-frequency representation of EEG spectral power during task performance. The delay period is from 12 to $18 \mathrm{~s}$. The figure is taken from Boonstra et al. (2013) with permission from Elsevier.

Proskovec et al. (2018) in a MEG study localized theta in the left dorsolateral prefrontal cortex and reported an increase, but their figure 3 shows the opposite pattern: after a short transient increase, theta decreased below baseline level and maintained in this state until probe presentation. Contrary to the results by Proskovec, theta continuously increased during the delay period in two EEG studies in exactly the same paradigm (Berger et al., 2019; Eschmann, Bader, \& Mecklinger, 2018). The spatial WM task employed by these three studies was first published in EEG study by Griesmayr et al. $(2014)^{1}$, which also reported a theta increase.

Similarly to the verbal WM study by Harmony et al. (1996), four visual WM studies reported a decrease of theta only in the conditions with very low WM load. Babiloni et al. (2004) used a task where only the result of the height comparison of two clearly different bars had to be maintained, not the sensory information per se. Three other studies used a one item WM paradigm (Bastiaansen, Posthuma, Groot, \& de Geus, 2002; de Vries, Savran, van Driel, \& Olivers, 2019; Kulashekhar, Pekkola, Palva, \& Palva, 2016).

A similar pattern was found in the study by Rawle et al. (2012, p. 8) who wrote: "The loaddependent depression of theta during the memory delay, in a frontal distribution, agrees with the findings of Bastiaansen et al. (2002), who proposed that delay-period frontal desynchronization of theta activity is related to visuospatial working memory function". This hypothesis is partially supported by the data above: verbal WM studies reported an

\footnotetext{
${ }^{1}$ not included in the review because of clinical population
} 
increase in theta significantly more frequently than visual ones (19/24 and 14/32 respectively, $\left.\chi^{2}=7.12, p=0.008\right)$. Nevertheless, Khader et al. (2010) used both modalities and found no significant differences in the theta expression.

No specific details can differentiate the last study with theta decrease (Yin et al., 2012) from similar ones where the opposite pattern was observed. Like most visual WM the study used a DMTS paradigm. Temporal order information is relevant in the Sternberg task but redundant in the DMTS type of task. This gets us back to the hypothesis on the role of theta oscillations and its relation to the maintenance of items' order in WM (Hsieh et al., 2011). If theta is indeed important for the maintenance of the temporal relationship between the items in WM, then looking at the type of task may help to clarify the answer to this question.

A systematic analysis of the experimental paradigms used in the 32 visual WM studies, allowed us to subdivide them into two main groups: (1) DMTS type of task where no temporal information is stored in WM (26/32), (2) other paradigms with the temporal order information required to complete the task (6/32). 4/6 of serial order paradigms and 10/26 DMTS-like paradigms reported an increase in theta activity during the delay. The proportions were not significantly different $\left(\chi^{2}=1.58, p=0.209\right)$.

\subsection{Alpha}

In twenty-seven of 35 verbal WM studies, alpha rhythm was featured in the results or depicted in figures. Twenty studies varied WM load in two or more levels. A change in alpha activity as a function of increasing load (stepwise change) was observed in 15 of them. In two cases no stepwise load-dependent alpha change in any direction was observed (Harmony et al., 1996; Kwon et al., 2015). A saturation effect was observed in two studies (Bashivan et al., 2014; Xie et al., 2016, see below). In one study the effect was neither statistically tested nor presented in a graphical form (Klimesch, Schimke, \& Pfurtscheller, 1993). These results generally replicate the findings in theta frequency band - most studies report stepwise changes in alpha power.

However, when compared with theta activity, there was more discrepancy concerning the direction of the effects. A clear load-related increase of alpha activity was observed in $18 / 27$ studies. In four studies there was a decrease of alpha during the delay period, and 
one study did not find significant changes in alpha during the delay. In the remaining six studies the results were more complex. In two studies alpha increased in the 4-items condition as compared with the 2-items condition, but no further increase in the 6-and 8-items conditions was observed (saturation effect) (Bashivan et al., 2014; Xie et al., 2016). Michels et al. (2008) distinguished two groups of subjects ( $N=9$ in each group): $a$ group where alpha increased with WM load and another group where alpha decreased. Interestingly, but not surprisingly, in two other studies conducted by the same group on the same topic, no individual differences in alpha reactivity were reported anymore (Kottlow et al., 2015; Michels et al., 2010). One study reported an increase of alpha in a right occipital channel but a decrease in a midline parietal channel (Kottlow et al., 2015). Similarly, in another study alpha activity increased with load in the right posterior channels but decreased in all other channels (Pavlov \& Kotchoubey, 2017). Finally, Okuhata et al. (2013) found that alpha modulation depended on the type of stimulus presentation.

As already said above, stimuli in verbal WM tasks can be presented either simultaneously or successively. Okuhata et al. (2013) directly compared the two types of presentation and reported a stepwise increase of alpha in the successive presentation condition, but a decrease in the simultaneous presentation condition. In line with Okuhata et al. (2013), another group of authors also suggested that alpha activity mainly occurs in the tasks requiring maintenance of simultaneously presented information (Hsieh et al., 2011). We found that the majority (20/35) of the studies used simultaneous presentation and the other 14 used successive presentation. The above-mentioned study of Okuhata et al. (2013) compared both presentation types. Using only 23 studies yielding unambiguous findings, we found no significant difference in the direction of alpha modulation between simultaneous (12/14 showed an increase) and successive (6/9 showed an increase) presentation $\left(\chi^{2}=1.17, \mathrm{p}=0.279\right)$. Similarly, although the number of studies in the two categories was very disproportional, visual WM studies using DMTS (26/46 showed an increase) vs serial order (4/7 showed an increase) paradigms did not differ in terms of frequency of an increase in alpha $\left(\chi^{2}<0.01, \mathrm{p}=0.975\right)$.

Another hypothesis was put forward in a narrative review of van Ede (2018) who selectively compared a few studies using either visual or verbal WM tasks. The author suggested that the sign of alpha modulation depends on the nature of memoranda: visual 
content maintenance results in alpha suppression and verbal content maintenance leads to alpha enhancement. We tested this hypothesis in the current work. As stated above, after the exclusion of mixed results, alpha increase was found in 78\% (18/23) verbal WM studies and in 57\% (30/53) visual WM studies, with the difference approaching significance $\left(\chi^{2}=3.23, p=0.072\right)$. Thus, the increase of alpha activity is generally a frequent finding (almost 2/3 studies), but the modality of WM may partially contribute to the discrepant results.

In three visual WM studies (excluded from the analysis above) higher frequency alpha increased with load but lower frequency alpha decreased (Daume, Graetz, Gruber, Engel, \& Friese, 2017; Daume, Gruber, Engel, \& Friese, 2017; Maurer et al., 2015). We tested whether there is a clear distinction between the directionality of the effect between lower alpha (below $10 \mathrm{~Hz}$ ) and higher alpha (above $10 \mathrm{~Hz}$ ) in verbal WM studies that reported a decrease during the delay. None of the six studies with alpha decrease separated alpha into subbands. In one study the time-frequency maps allowed to track alpha in the subbands but no visually observable difference between them was noticeable (Kwon et al., 2015). Then we inspected all studies where time-frequency maps allowed us to observe changes in both alpha subbands. In short, no studies reported the sought difference between the subbands. Instead, the frequency range of the alpha effect tended to vary between studies: the effect covered both subbands in some studies (Bonnefond \& Jensen, 2012; Heinrichs-Graham \& Wilson, 2015; Hu et al., 2019; Jensen, Gelfand, Kounios, \& Lisman, 2002; Kustermann et al., 2018), whereas it occupied higher alpha frequencies in others (Hu et al., 2019; Michels et al., 2010; Proskovec, Heinrichs-Graham, et al., 2019; Scheeringa et al., 2009; Wianda \& Ross, 2019), but no studies reported specific alpha changes in the lower alpha subband. Interestingly, Proskovec et al.'s (2019) and Heinrichs-Graham \& Wilson's (2015) studies were conducted in exactly the same paradigm by the same group but the alpha effect was found either in both alpha bands or only in the higher alpha, without an explanation. Similarly, Hu et al., 2019 reported two studies with different alpha bands in one and the same article.

In some of the reviewed studies, the alpha increase during the delay was prominently right side lateralized (i.e., more alpha in the right hemisphere, see Table 1 and 2). Note that the stimuli in these studies were always presented in the middle of the screen and there were no lateralized or spatial cues. The results of the systematic review 
demonstrate a prevalence of right-lateralized alpha in verbal WM tasks (see Table 1). In the EEG studies where topographical maps were reported, the alpha increase effect had no asymmetry in 3/19, right asymmetry in 16/19 studies, and no studies reported left side asymmetry. Moreover, of the 28 visual studies with a symmetrical presentation of the stimuli and available topoplots, 19 studies reported no asymmetry, and 9 reported right hemisphere asymmetry. The proportion of studies reported right side asymmetry was larger in verbal than in visual WM $\left(\chi^{2}=12.3, \mathrm{p}<0.001\right)$.

Bashivan et al. (2014) among others noticed that alpha saturated with no further modulation after 4 items load. We tested whether this effect characterized other studies that varied load at 4 and higher levels of load (e.g., at least compared 4 vs 5 items load). One MEG study and 11 EEG studies in the verbal WM domain were identified applying this criterion.

Xie et al. (2016), similarly to Bashivan et al. (2014), showed a saturation of alpha changes at 4 items load. Scheeringa et al. (2009) found a significant difference between 3 and 5 but not between 5 and 7 items load. Although Michels et al. (2008) claimed that the effect of alpha was modulated by individual differences (see above), the effect of load (any of the 4 vs 6 vs 8 items comparisons) was not significant on the group level. Meltzer et al. (2007) failed to identify a stepwise modulation of alpha but no pair-wise comparisons were conducted. On the other hand, Wilson, Swain, \& Ullsperger (1999) found that alpha suppression was stronger at 7 and 8 items load as compared with 5 items load. It is unclear whether there was a significant difference between 7 and 8 items. 5 vs 7 items contrast was significant in another study (Pavlov \& Kotchoubey, 2017). The increase of alpha from 4 to 6 items load was significant in Jensen et al. (2002), but the effect was manifested over the central-frontal-temporal area instead of the alpha-typical posterior areas of the cortex. Similarly, another study reported that alpha increased significantly in the comparison of 4 and 6 items load (Proskovec, Heinrichs-Graham, et al., 2019). Klimesch et al. $(1993,1999)$ in two studies used a combination of letters and digits (5 vs 10 items load). Both studies showed the effect of load on alpha activity during the delay. Thus, both tendencies - a saturation of alpha with load and continuation of changes were present in the verbal WM subset.

To test the specificity of this result, we inspected the corresponding studies in the visual WM subset. Seven of 55 studies (one MEG and six EEG studies) compared at least two 
levels of load above 3 items. However, in four of the 7 studies, the effect was neither formally tested by pairwise comparisons nor it was possible to infer the effect from the figures or other analyses (Erickson, Smith, Albrecht, \& Silverstein, 2019; Moran et al., 2010; Pahor \& Jausovec, 2017; Spitzer, Fleck, \& Blankenburg, 2014). In the remaining three studies the saturation effect took place. In two studies the comparison of 4 with 6 items load did not yield significance (Kawasaki \& Yamaguchi, 2012; Nenert, Viswanathan, Dubuc, \& Visscher, 2012). In another study alpha monotonically decreased up to 3 item load (not even 4) (Fukuda et al., 2015).

\subsection{Beta}

Fifteen of 35 studies featured beta frequency band $(13-30 \mathrm{~Hz})$ in the results or depicted in figures. Of these 15, three studies reported null findings, five studies showed beta suppression, and four studies reported beta increase during the delay. One study reported an increase of beta in occipital and a decrease in frontal areas (Altamura et al., 2010). In another study, beta increased with load at occipital channels but decreased with load at parietal ones (Kottlow et al., 2015). In one study higher beta increased at frontal sites in the high-performance group but increased at posterior sites in the lowperformance group (Pavlov \& Kotchoubey, 2017).

In contrast to theta rhythm that primarily covers frontal cortical areas and alpha that covers posterior areas of the brain, beta rhythm has no typical spatial distribution. In five studies beta was analyzed at posterior sites (Bashivan et al., 2014; Heinrichs-Graham \& Wilson, 2015; Kottlow et al., 2015; Michels et al., 2010; Pavlov \& Kotchoubey, 2017), in other five studies at frontal sites (Brookes et al., 2011; Itthipuripat et al., 2013; Onton et al., 2005; Park et al., 2013; Wilson, Swain, \& Ullsperger, 1999), and in four studies both frontal and posterior sites were included into the analysis (Altamura et al., 2010; Gao, Sun, Yang, \& Gong, 2018; Poch et al., 2010; Stephane et al., 2010). In one study (Wianda \& Ross, 2019) continuous beta suppression over the left central area was shown, whereas the occipital beta behaved similarly to alpha and increased during WM delay.

Frequencies and spatial distributions of the beta effects varied substantially. Only lower beta or beta1 (typically 13-20 Hz) was analyzed in four studies (Heinrichs-Graham \& Wilson, 2015; Michels et al., 2010; Onton et al., 2005; Park et al., 2013), higher beta or beta2 (20-30 Hz) in three studies (Brookes et al., 2011; Pavlov \& Kotchoubey, 2017; 
Wilson et al., 1999), and in eight studies the whole frequency band or both subbands were inspected (Altamura et al., 2010; Bashivan et al., 2014; Gao et al., 2018; Itthipuripat et al., 2013; Kottlow et al., 2015; Poch et al., 2010; Stephane et al., 2010; Wianda \& Ross, 2019).

No particular pattern of beta activation/suppression in these studies was related to the spatial distribution: beta could alternate in the frontal as well as in the posterior areas equiprobably; likewise, the frequency subband was not predictive of the direction of the effect.

The comparative results from the visual WM literature were as diverse as the results of verbal WM studies. Out of twenty-one visual WM studies featuring beta in the results, the

majority (12) reported a decrease, but eight studies reported an increase of beta activity during the delay. One study found a decrease of the central beta but an increase of posterior beta (Park et al., 2011). In the same study alpha activity also decreased under WM load. Based on this finding we hypothesized that posterior beta might be an alpha harmonic and, therefore, share the behavior of the alpha rhythm. There were eight verbal and 16 visual WM studies where the data were specifically reported for the posterior alpha and beta. In seven verbal and 13 visual WM studies (i.e., in $83 \%$ of all studies) the alpha and beta varied in the same direction.

\subsection{Gamma}

Gamma activity in verbal WM tasks is even less well studied than beta activity. Gamma results were featured in three of 25 EEG and three of 10 MEG studies. In two EEG studies, null findings were reported. One study reported an increase in gamma activity during the delay. Of the three MEG studies, one demonstrated a decrease of beta/low gamma oscillatory power with increasing WM load (Brookes et al., 2011), one study showed, in contrast, an increase of gamma activity (Poch et al., 2010), and one study did not reveal any changes in gamma with load (Kustermann et al., 2018).

In the visual domain, the sample was larger. Five visual WM studies using EEG featured gamma activity in the results. Two of them yielded null findings (Rawle et al., 2012; Zhang, Zhao, Bai, \& Tian, 2016). Gamma decreased in two other studies (Pahor \& Jausovec, 2017; Smyrnis et al., 2014). In one study gamma quickly disappeared after an initial ( $800 \mathrm{~ms}$ ) increase (Tallon-Baudry, Kreiter, \& Bertrand, 1999). Twelve similar 
studies were carried out with MEG, seven of which reported an increase in gamma during WM maintenance. No changes were found in four studies. In one MEG study, gamma increased over posterior and right temporal regions but decreased over left temporal and central areas (Park et al., 2011).

Thus, summarizing over verbal and visual domain studies, the results reveal a strong difference between the two recording modalities: a sustained increment of gamma activity was obtained in most (8/14) MEG studies but in one (1/8) EEG study $\left(\chi^{2}=4.19\right.$, $\mathrm{p}=0.04)$.

\section{Discussion}

\subsection{Theta}

\subsubsection{Temporal order hypothesis}

The importance of frontal midline theta in verbal WM maintenance was supported by the majority of the reviewed studies: theta power was higher during the delay period in comparison with baseline.

Presumably, theta activity plays a role in the maintenance of the temporal relationship between the items in memory: storage of a larger number of items makes the relationship more complex (Hsieh \& Ranganath, 2014). Another study conducted by the same group supports this idea (Roberts, Hsieh, \& Ranganath, 2013). In this study, the participants required to remember either location of 4 presented sequentially abstract images or the temporal order of the images. The order condition generated stronger theta power.

It appears to be difficult to design a task that could provide sufficient evidence for or against this hypothesis in the verbal domain. Moreover, even presented simultaneously verbal content is rehearsed in a sequence. Nonetheless, we suggest that the hypothesis can be tested in the verbal WM domain in three ways. First, by comparison of single-item WM load, when no temporal relationship between items exists, with higher load conditions. Onton et al. (2005) demonstrated the expected pattern of load-dependent increase of theta power (see Figure 5). Unfortunately, the delay period after the presentation of the items was too short to make a reliable conclusion. Out of 56 verbal 
and visual WM available studies, this is the only one where this kind of comparison could be made. Second, the explicit task to memorize order and content in one condition and to memorize only content in another one could shed some light on the matter. For example, sufficient evidence could come out of a comparison of the classic Sternberg paradigm with a single item probe and a modified Sternberg paradigm with a requirement to remember both content and order, similar to the ones used in Pavlov \& Kotchoubey (2017) or Wianda \& Ross (2019). To date, there are no such studies. Third, more studies manipulating WM load in a wide range can provide additional evidence in support for the hypothesis, provided that the difficulty of the task is equalized over conditions.

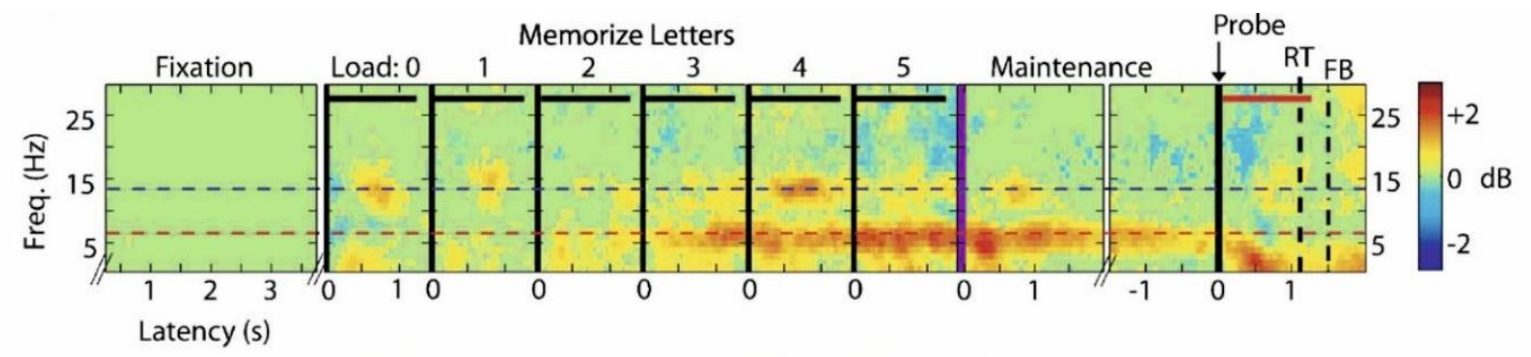

Figure 5 - Development of FMT enhancement with increasing load from 0 to 5 items in a verbal WM task. Black horizontal bars represent the encoding period (the figure is adapted from Onton et al. (2005) with permission from Elsevier)

\subsection{Alpha}

\subsubsection{Directionality}

Alpha activity was another popular target in the reviewed studies. In contrast to theta, the directionality of alpha modulation varied: after the exclusion of mixed and null findings, about $20 \%$ of the verbal WM studies detected a decrease and $80 \%$ an increase in alpha power during the delay. The proportion of visual WM studies was close to 40/60\%. To explain this discrepancy, we tested several hypotheses and rejected all of them with different degrees of certainty. On the one hand, the modality (visual vs verbal) and type of presentation (simultaneous vs successive) failed to fully explain the alpha directionality. On the other hand, there is not enough information on the impact of alpha subband frequency (lower vs upper alpha) and individual differences on the direction of changes in alpha power. 
Alpha suppression has been seen as a sign of cortical engagement allowing either encoding of information into WM or decoding the information for retrieval (Jensen \& Mazaheri, 2010; Klimesch, Sauseng, \& Hanslmayr, 2007). When simultaneously presented verbal stimuli remain on the screen for a long time (3s or longer) alpha is continuously suppressed over the encoding period (Bailey, Segrave, Hoy, Maller, \& Fitzgerald, 2014; Murphy et al., 2019; Scheeringa et al., 2009; Segrave et al., 2010). Whereas alpha increase during the delay may reflect sensory gating through the disengagement of certain cortical areas to protect memory representations from interference (Klimesch et al., 2007; Payne \& Sekuler, 2014; Roux \& Uhlhaas, 2014). In the case of visual presentation, alpha supports the storage of the memory items by blocking visual input. We can hypothesize that the cases when alpha activity is suppressed during the delay are the cases when visual information processing is still ongoing.

Attention is able to selectively suppress alpha activity spatially related to a specific memory representation (de Vries, van Driel, Karacaoglu, \& Olivers, 2018; Fukuda et al., 2015; Schneider, Goddertz, Haase, Hickey, \& Wascher, 2019). For example, when internal attention is directed with a previously presented cue (retro-cue) to the left hemifield items maintained in WM, right posterior alpha activity is attenuated (de Vries et al., 2018; Myers, Walther, Wallis, Stokes, \& Nobre, 2015; Sauseng et al., 2009; Wolff, Jochim, Akyürek, \& Stokes, 2017; Worden, Foxe, Wang, \& Simpson, 2000). Thus, although visual input is blocked during the delay, previously presented spatial cues may direct internal attention and affect alpha activity.

A few properties of these studies complicate the interpretation of the alpha suppression in WM tasks with retro-cues. First, most of the above-mentioned studies used short delays which do not help to separate pure oscillatory effects from ERPs. Second, a lot of these kinds of studies only report the index of lateralized alpha (for this reason they were excluded from the review). Without having access to spectral power data from both hemispheres, it is difficult to say whether alpha was generally suppressed during the delay or less strongly enhanced in the contralateral hemisphere.

We can assume that in a typical WM task without retro-cues (e.g., Sternberg task), the item currently in the focus of attention suppresses alpha, while the items currently outside the focus enhance alpha at the same time. Both operations may engage such local neuronal populations that M/EEG cannot spatially differentiate them. But what is 
happening when there is only one item to store? Then alpha shows a small magnitude increase anyway (e.g., see Figure 6).
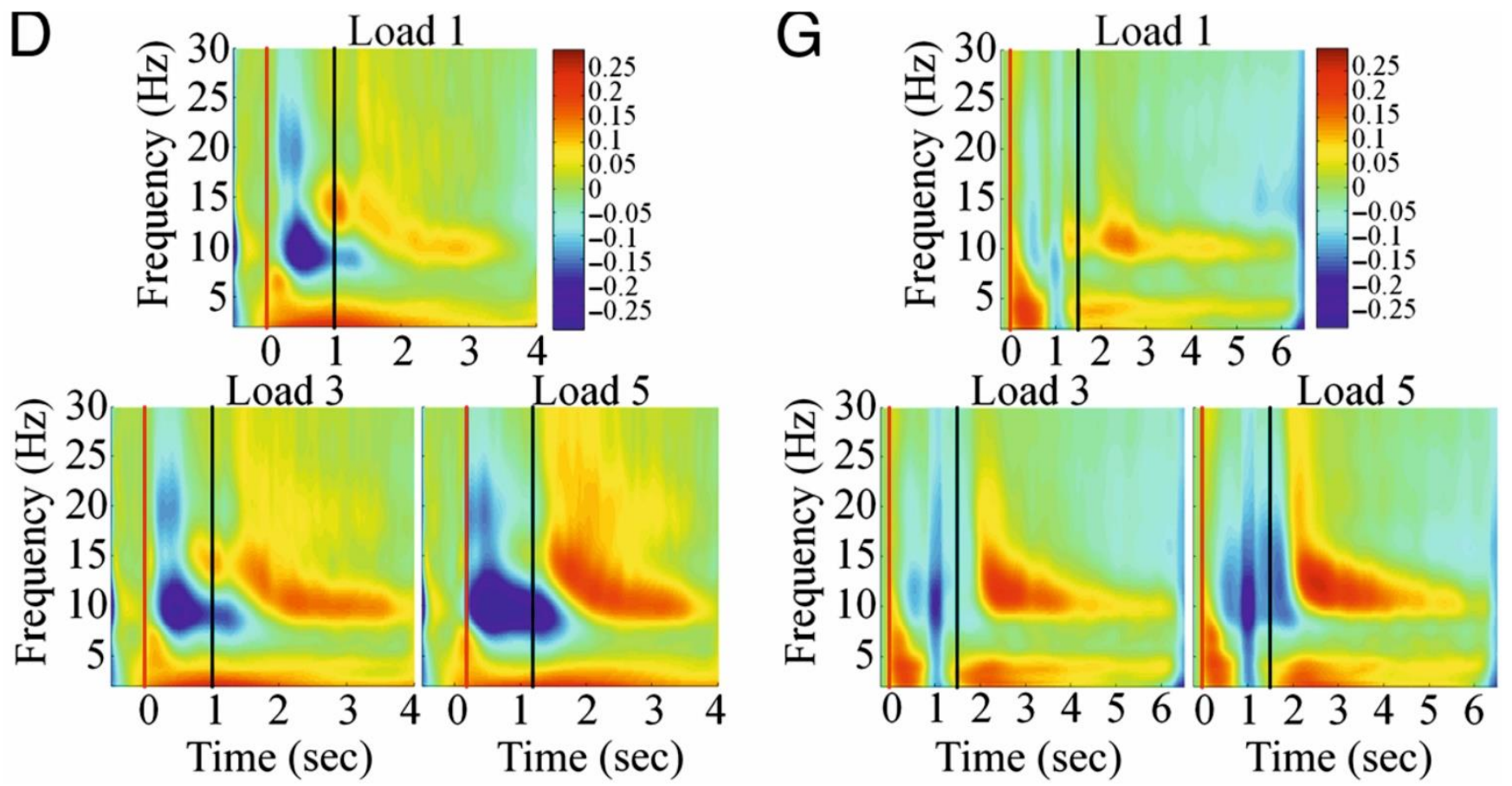

Figure 6 - Alpha activity during the delay in two verbal WM paradigms (D: Sternberg, G: DMTS). Adopted from figure 3 in Hu et al. (2019) with permission from MIT press. The black vertical lines mark the beginning of the delay period.

The existing data exhibits a striking contrast between a large number of available studies and the inability to predict, not the magnitude, but even the direction of alpha modulation. Before we start building a mechanistic foundation of the role of alpha activity in the maintenance of $\mathrm{WM}$, more replication studies are deemed necessary.

\subsubsection{Asymmetry}

A stronger increase of alpha in the right hemisphere is common in many verbal WM tasks. If we accept the mainstream interpretation, an increase of alpha during the delay serves to prevent the sensory cortex from further processing of information, thus protecting stored memory from interference (Bonnefond \& Jensen, 2012; Foxe \& Snyder, 2011; Jensen \& Mazaheri, 2010; Klimesch et al., 2007). Putting it differently, the current view suggests that alpha represents a mechanism of active inhibition of irrelevant cortical areas (Klimesch et al., 2007). 
But why should the activity of the right temporo-parieto-occipital region during a WM task performance be irrelevant? We suggest that the maintenance of verbal information presented visually dissociates two simultaneous demands: blockage of visual input by disengaging visual cortex and activation of the language cortex for rehearsal. The rehearsal processes involve left posterior regions, which is reflected in the suppression of alpha in the left hemisphere. The opposite task to inhibit distracting visual input enhances alpha activity in both hemispheres.

The same kind of alpha asymmetry was found in visual WM studies, though significantly less frequently. The mechanism generating the asymmetry in non-verbal tasks is less clear. Johnson et al. (2011) used tasks requiring either memorizing shapes of objects or their location. The right-side (left < right) alpha asymmetry revealed itself only in the shape condition, while alpha was symmetrical in the location condition. Moreover, alpha was generally stronger in the shape condition. Perhaps, maintenance of spatial information suppressed alpha in the right hemisphere thus equalizing it over the posterior cortical areas. However, Bastiaansen et al. (2002) showed stronger alpha over the right occipital area in a spatial task. Although the prevalence of right-side alpha asymmetry among all reviewed studies associated with the content stored in memory (verbal or visuo-spatial), the origin of the alpha asymmetry in visual WM demands more systematic investigation.

The natural alpha asymmetry in the resting state also might contribute to the effect (Allen \& Cohen, 2010; Ocklenburg et al., 2019; Stewart, Coan, Towers, \& Allen, 2014; van der Vinne, Vollebregt, van Putten, \& Arns, 2017). However, the effect was also present in many studies where alpha power was normalized on baseline. Thus, the asymmetry during the delay was a sign of a genuine increase in alpha asymmetry, not preservation of the status quo.

\subsubsection{Saturation}

In some of the reviewed studies, alpha power did not change with WM load beyond the theoretically predicted (Cowan, 2001; Oberauer et al., 2018) average individual WM capacity limit of 4 items. This reminds the behavior of P300 that also stops to change at higher levels of WM load in the classical version of the Sternberg task (Kotchoubey, 2002). Another ERP component, contralateral delay activity (CDA), also saturated in the 
change detection paradigm (Luria, Balaban, Awh, \& Vogel, 2016). Similarly, fMRI BOLD signal increased monotonically with load up to the individual's WM capacity that averaged at 4 items set-size (Todd \& Marois, 2004). Although some studies confirmed the saturation of alpha in verbal WM, the effect was not as consistent as in the case of CDA.

In the visual domain, all the identified studies showed saturation of non-lateralized alpha (as opposed to lateralized alpha in the lateralized change detection paradigm) at higher levels of load. It should be taken into account, however, that only a few visual WM studies used set-sizes above 4 items.

If it is true that the saturation of alpha is necessary in visual WM tasks but can sometimes be avoided in verbal WM tasks, this difference may reflect an effect of chunking, i.e., the grouping of WM items (chunks) into larger units. Thus, for example, the task to encode a string of nine digits is feasible because the string is automatically converted into 3 threedigit numbers. The 4 items WM limit proposed by Cowan (2001) refers to a condition when rehearsal and chunking are restricted. When rehearsal of verbal material such as digits or letters is not blocked, then the capacity limit reaches the number of items an individual can rehearse in about 2 s (Baddeley, 1996; Cowan, 2001). The capacity increases further if chunking is possible. These are, probably, the reasons why set-sizes above 4 items, as frequently used in verbal WM research, do not overload average WM capacity.

\subsection{Beta}

Beta oscillations in verbal WM research are much less studied than alpha and theta. The review has shown a wide diversity of effects in the beta frequency band. An assumption that there is probably more than one beta rhythm may contribute to the explanation of the discrepancy in the effects. These beta rhythms may occupy different frequencies, have different temporal and spatial distribution, and, therefore, different functional meanings. The data present strong evidence that occipital beta may be a harmonic of alpha and does not play an independent functional role. The role of beta oscillations outside occipital regions in WM remains unclear. 


\subsection{Gamma}

Even though intracranial EEG (iEEG) and MEG repeatedly demonstrated the robustness of gamma responses in cognitive tasks (Herrmann, Fründ, \& Lenz, 2010; Jerbi et al., 2009), gamma obtained from the EEG signal is less robust. The reason for this is strong contamination of EEG by muscle artifacts mainly occupying higher frequencies including the gamma frequency band (Muthukumaraswamy, 2013). Generally worse signal-tonoise ratio in the gamma band of the EEG signal may explain less attention to gamma oscillations in EEG in verbal WM tasks. Interestingly, only a single EEG study reported gamma increase during the delay in the combined whole dataset of 65 studies employing this method. Contradicting our expectations, a few EEG studies even reported a decrease in gamma power.

To understand how signal-to-noise ratio might have affected our results we extracted data from a representative sample of iEEG studies. To achieve that, we used similar criteria applied to the M/EEG dataset to identify the iEEG studies featuring gamma rhythm in the results. In sharp contrast to EEG, the increase of gamma power with load was confirmed in six of nine available verbal WM iEEG studies (Bahramisharif, Jensen, Jacobs, \& Lisman, 2018; Gehrig et al., 2019; Howard et al., 2003; Kambara et al., 2017; Mainy et al., 2007; Meltzer et al., 2008). Even this high percentage (67\% "positive" findings) can be an underestimation. Of the three studies with "negative" findings, two studies recorded iEEG from the hippocampus (Boran et al., 2019; Leszczyński, Fell, \& Axmacher, 2015), which cannot be directly compared with the cortical iEEG. Finally, the last study (Raghavachari et al., 2001) briefly mentioned that gamma activity was affected by load but the results are reported elsewhere. Unfortunately, we were unable to identify the referenced study.

The present systematic review includes only studies performed with healthy participants unaffected by any drugs. The compared group of the nine iEEG studies involved, in contrast, neurological (mainly epileptic) patients, most of them were medicated. Although the difference is important, we cannot imagine how epilepsy or antiepileptic drugs might improve gamma responses making them more clear and consistent. Moreover, the iEEG data are corroborated by the results of MEG studies, $60 \%$ of which showed an increase in gamma activity during the delay. However, most of those included 
in this analysis studies used visual WM tasks, whereas the sample of verbal WM studies featuring gamma was small.

\subsection{EEG vs MEG}

Alpha and beta bands did not differentiate the results obtained by any of the methods but theta and gamma did.

Whereas iEEG and partially MEG linked sustained gamma with the maintenance of WM, EEG failed to provide such evidence. Only a single EEG study reported some gamma modulation during WM delay. Until more convincing evidence is available, the whole enterprise of extracting meaningful quality data from the EEG in the gamma frequency band raises doubt. Perhaps, we even have a reason to be skeptical about the studies employing different approaches such as theta-gamma cross-frequency coupling.

EEG and MEG disagreed less strikingly but sufficiently in the theta band: EEG verbal WM studies almost unanimously showed an effect of increased theta during the delay, but MEG findings exhibited less consistency. A possible reason for this difference may be the specific sensitivity of the MEG signal to the orientation of the current dipole. MEG is sensitive to the activity generated in sulci of the cortex (i.e. in sources tangential to the head surface) but blind to radially oriented sources. The strongest theta sources are located in the medial prefrontal cortex and directed perpendicularly to the scalp. This distribution of the magnetic fields prevents it from being registered by MEG. A simultaneous M/EEG recording in the Simon task (a task that reliably generates FMT in EEG) showed a less focused, more lateral, and individually different pattern of theta activity in MEG (Zuure, Hinkley, Tiesinga, Nagarajan, \& Cohen, 2020).

The results in gamma and theta bands highlight the difference between EEG and MEG in the methodology and probably in the underlying biophysical mechanisms. At least in some cases, results obtained by MEG and EEG should be interpreted interchangeably with caution.

\subsection{Verbal vs Visual WM}

In the final section, we ask: Does WM for visually presented verbal stimuli differ from visual WM? Or can verbal WM, on the basis of the electrophysiological data, be considered 
as a special case of visual WM? The answer is, paralleling behavioral studies (Oberauer et al., 2018), electrophysiology of verbal WM differs from that of visual WM.

Verbal WM studies reported an increase in theta significantly more frequently than visual ones $\left(19 / 24\right.$ and $14 / 32$, respectively, $\left.\chi^{2}=7.12, p=0.008\right)$. Moreover, eight visual WM studies even indicated a significant decrease in theta. No such finding was found in the verbal WM domain. A hypothesis is that theta is important for the maintenance of temporal order which is of stronger demand in the verbal tasks.

In contrast to the significant effect of modality on theta modulation, a similar difference in the alpha band was less convincing. However, right hemisphere asymmetry in alpha power (right > left) was reported more frequently in the verbal domain. This effect is the most prominent influence of the verbal content that supposedly activates primarily left located language cortical areas, thus suppressing alpha in the left while enhancing alpha in the right hemisphere. Another difference may be the saturation effect, which was less prominent in the verbal than in the visual domain; but we should keep in mind that the sample size of this subset of studies was rather small.

Considering a large diversity in frequency and spatial characteristics of beta activity it might be too preliminary to make any certain conclusion about verbal/visual differences in beta oscillatory responses. Nevertheless, the delay beta power showed a similar increase in $7 / 20$ of visual and $4 / 15$ of verbal studies $\left(\chi^{2}=0.12, p=0.727\right)$.

Finally, as compared to verbal, more visual gamma studies (1) featured the rhythm in the results, and (2) reported an increase of gamma power during the delay (although not significantly, verbal: $2 / 6$, visual: $7 / 16, \chi^{2}=0.19, \mathrm{p}=0.658$ ). We cannot rule out that the latter depended on the former, i.e., the null results were simply not reported. The question of whether gamma activity is more associated with visual than with verbal information processing remains difficult to answer. Such studies cannot be conducted in animals, and human iEEG study would require recordings from larger areas than possible and ethically justifiable (Parvizi \& Kastner, 2018). More MEG studies engaging different WM modalities may provide such evidence.

To summarize, a number of differences between the modalities exist: verbal WM is leftlateralized (left < right alpha power), probably, has a larger capacity, and is more dependent on theta activity. 


\subsection{Limitations, Challenges, and Perspectives}

A certain level of simplification and generalization is inevitable in any review of the literature. The issue is even more severe in a systematic review aiming to accommodate as many studies as possible while maintaining objectivity and precision in the quantification of the results. This holds true even if the quantification involves only identifying the direction of the effect with three viable options. More thorough data quantification would necessarily mean taking steps to decrease heterogeneity, resulting in a much smaller sample and narrower scope of the review. We admit that we are only scratching the surface of the literature by application of this simplistic approach, and the current work might be only a small step away from a pure narrative review. But reading those hundreds of M/EEG papers published over the years has left an impression that most discussion sections mainly compare their results with similar previous findings, avoiding even to mention studies that obtained the opposite effect. Our review creates a context for future research to make this behavior less likely to occur.

A review can only analyze variables that vary from study to study systematically, but not chaotically. We thus considered only factors that could build reasonably large groups of studies. Even this cautious approach resulted in some unbalanced comparisons. Other smaller factors may contribute to the inconsistencies in the reviewed findings. Potentially, the decisions in the analysis pipeline such as length of the time window used in Fourier transform (or other similar parameters for Hilbert transform or wavelet analysis), analysis time window, filter settings, number of trials, selection of the channels and reference scheme, duration of baseline, definition of the frequency bands (e.g., alpha can vary in the range between $8-13,7-14,10-12 \mathrm{~Hz}$, or can be selected on the basis of individual alpha frequency), application of independent component analysis (ICA) (to source or sensor space data) for source separation and many other factors could affect the results. The heterogeneity of the studies included in the review prevented us from assessing the impact of these factors.

A pure description of the analysis pipelines is also beyond the scope of the current review. Descriptive data are only helpful if the experimental paradigms in the original studies are almost identical. Thus, selecting studies using the same experimental paradigm is an essential step in a search of the methodological aspects contributing to the variability of 
results. A promising example of such a study looked at all possible ways to analyze N400 ERP in the visual modality in a sample of 132 studies (Šoškić, Jovanović, Styles, Kappenman, \& Kovic, 2020). Another possibility to solve this problem is to apply a multiverse analysis to the raw data. Going in this direction would involve deep participation of the original authors and/or broader adoption of the data-sharing practices.

Conflicting findings even within one study, missing methodological details, and a vague description of the results may lead to misrepresentation or imprecise quantification of studies in any review of the literature. We believe that - devised by an authoritative board of M/EEG and WM experts - methodological recommendations would benefit the field by mitigating the negative effects of reporting inconsistency among studies. To ensure an extensive adoption, these recommendations should necessarily be supplemented by simple machine- and human-readable check-lists/interactive forms. Of course, the present article never aimed to develop such recommendations.

Apart from widely adopted analytic approaches to brain oscillations, such as FFT and wavelet analysis, novel techniques have been proposed, some of them quite recently (Cole \& Voytek, 2019; Donoghue et al., (in press); Kosciessa, Grandy, Garrett, \& WerkleBergner, 2020). On the one hand, we cannot rule it out that one of these methods would make a breakthrough in the study of cognitive functions, and particularly working memory; on the other hand, singular adoption of them will further increase the already high methodological variability, and further decrease the comparability of results. The experience tells us that cognitive neuroscientists rarely hasten to embrace novel computational techniques after the release. Whether we should regard this conservatism as an advantage or disadvantage remains unclear.

\subsection{Conclusions}

1. In the pool of thirty-five identified verbal and sixty-five visual WM studies, oscillatory EEG responses in theta, alpha, beta and gamma frequency bands were analyzed in 25,27 , 15, 6 verbal and 32, 56, 21, 17 visual WM studies, respectively. A significant amount of the reviewed literature supports the role of theta and alpha oscillations in WM though much less is known about the role of beta and particularly gamma activity. 
2. Theta activity increases with WM load in verbal tasks, whereas this trend is less pronounced in visual WM tasks. This may be related to the larger role of theta in building a temporal structure for the maintenance of multiple items in verbal WM.

3. Alpha activity changes with increasing WM load, but the direction of the effect is not consistent across the studies. In approximately $20 \%$ and $40 \%$ of the verbal and visual studies, respectively, alpha decreased with load, while in the other studies it increased. The direction of the modulation is not fully explained by the stimulus modality, type of the stimulus presentation (simultaneous or successive), and, as far as it is possible to judge on the basis of few studies, on individual differences. The reason for this fact remains to be elucidated.

4. The distribution of posterior alpha power had right hemisphere asymmetry (left < right) in the majority of the studies, even if sensory input was symmetrical. Significantly smaller amounts of visual WM studies showed this asymmetry. The effect is probably related to the leading role of the left hemisphere in verbal information processing.

5. The saturation of alpha at the theoretical limit of WM capacity (i.e., alpha responses change with WM load from 1 to 4 items, but remain stable above the 4 -item level) was found in several, but not in all verbal WM studies, and the reasons of the differences remain unclear. The saturation effect at 4 items load is more consistent in the visual WM literature.

6. Many MEG and iEEG studies report incrementing gamma activity during WM performance whereas EEG studies do not. This may indicate that the scalp EEG is not the best tool to study gamma oscillations in WM tasks.

\section{Acknowledgements}

The study was supported by Russian Foundation for Basic Research (RFBR) \#19-01300027. 


\section{References}

Allen, J. J. B., \& Cohen, M. X. (2010). Deconstructing the "Resting" State: Exploring the Temporal Dynamics of Frontal Alpha Asymmetry as an Endophenotype for Depression. Frontiers in Human Neuroscience, 4. https://doi.org/10/bpbc5w

Allen, M., Poggiali, D., Whitaker, K., Marshall, T. R., \& Kievit, R. (2018). Raincloud plots: A multi-platform tool for robust data visualization (No. e27137v1). https://doi.org/10.7287/peerj.preprints.27137v1

Altamura, M., Goldberg, T. E., Elvevag, B., Holroyd, T., Carver, F. W., Weinberger, D. R., \& Coppola, R. (2010). Prefrontal Cortex Modulation during Anticipation of Working Memory Demands as Revealed by Magnetoencephalography. Int J Biomed Imaging, 2010. https://doi.org/10.1155/2010/840416

Babiloni, C., Babiloni, F., Carducci, F., Cappa, S. F., Cincotti, F., Del Percio, C., ... Rossini, P. M. (2004). Human cortical responses during one-bit short-term memory. A highresolution EEG study on delayed choice reaction time tasks. Clinical Neurophysiology, 115(1), 161-170. https://doi.org/10.1016/S13882457(03)00286-4

Babiloni, C., Babiloni, F., Carducci, F., Cincotti, F., Del Percio, C., Della Penna, S., ... Romani, G. L. (2005). Human alpha rhythms during visual delayed choice reaction time tasks: A magnetoencephalography study. Human Brain Mapping, 24(3), 184-192. https://doi.org/10.1002/hbm.20079

Baddeley, A. (2003). Working memory: Looking back and looking forward. Nature Reviews Neuroscience, 4(10), 829-839. https://doi.org/10.1038/nrn1201

Baddeley, A. D., Hitch, G. J., \& Allen, R. J. (2019). From short-term store to multicomponent working memory: The role of the modal model. Memory \& Cognition, 47(4), 575588. https://doi.org/10.3758/s13421-018-0878-5 
Bahramisharif, A., Jensen, O., Jacobs, J., \& Lisman, J. (2018). Serial representation of items during working memory maintenance at letter-selective cortical sites. PLOS Biology, 16(8), e2003805. https://doi.org/10.1371/journal.pbio.2003805

Bailey, N. W., Segrave, R. A., Hoy, K. E., Maller, J. J., \& Fitzgerald, P. B. (2014). Impaired upper alpha synchronisation during working memory retention in depression and depression following traumatic brain injury. Biological Psychology, 99, 115-124. https://doi.org/10/f53bb3

Bashivan, P., Bidelman, G. M., \& Yeasin, M. (2014). Spectrotemporal dynamics of the EEG during working memory encoding and maintenance predicts individual behavioral capacity. European Journal of Neuroscience, 40(12), 3774-3784. https://doi.org/10.1111/ejn.12749

Bastiaansen, M. C. M., Posthuma, D., Groot, P. F. C., \& de Geus, E. J. C. (2002). Event-related alpha and theta responses in a visuo-spatial working memory task. Clinical Neurophysiology, 113(12), 1882-1893. https://doi.org/10/ch8zn6

Berger, B., Griesmayr, B., Minarik, T., Biel, A. L., Pinal, D., Sterr, A., \& Sauseng, P. (2019). Dynamic regulation of interregional cortical communication by slow brain oscillations during working memory. Nature Communications, 10(1), 1-11. https://doi.org/10.1038/s41467-019-12057-0

Blacker, K. J., Ikkai, A., Lakshmanan, B. M., Ewen, J. B., \& Courtney, S. M. (2016). The role of alpha oscillations in deriving and maintaining spatial relations in working memory. Cognitive, Affective \& Behavioral Neuroscience, 16(5), 888-901. https://doi.org/10.3758/s13415-016-0439-y

Bonnefond, M., \& Jensen, O. (2012). Alpha Oscillations Serve to Protect Working Memory Maintenance against Anticipated Distracters. Current Biology, 22(20), 1969-1974. https://doi.org/10/f4f3h2 
Boonstra, T. W., Powell, T. Y., Mehrkanoon, S., \& Breakspear, M. (2013). Effects of mnemonic load on cortical activity during visual working memory: Linking ongoing brain activity with evoked responses. International Journal of Psychophysiology, 89(3), 409-418. https://doi.org/10.1016/j.ijpsycho.2013.04.001

Boran, E., Fedele, T., Klaver, P., Hilfiker, P., Stieglitz, L., Grunwald, T., \& Sarnthein, J. (2019). Persistent hippocampal neural firing and hippocampal-cortical coupling predict verbal working memory load. Science Advances, 5(3), eaav3687. https://doi.org/10.1126/sciadv.aav3687

Brookes, M. J., Liddle, E. B., Hale, J. R., Woolrich, M. W., Luckhoo, H., Liddle, P. F., \& Morris, P. G. (2012). Task induced modulation of neural oscillations in electrophysiological brain networks. Neuroimage, 63(4), 1918-1930. https://doi.org/10.1016/j.neuroimage.2012.08.012

Brookes, M. J., Wood, J. R., Stevenson, C. M., Zumer, J. M., White, T. P., Liddle, P. F., \& Morris, P. G. (2011). Changes in brain network activity during working memory tasks: A magnetoencephalography study. NeuroImage, 55(4), 1804-1815. https://doi.org/10.1016/j.neuroimage.2010.10.074

Busch, N. A., \& Herrmann, C. S. (2003). Object-load and feature-load modulate EEG in a short-term memory task: NeuroReport, 14(13), 1721-1724. https://doi.org/10.1097/00001756-200309150-00013

Bushman, B. J., \& Wells, G. L. (2001). Narrative Impressions of Literature: The Availability Bias and the Corrective Properties of Meta-Analytic Approaches. Personality and Social Psychology

Bulletin,

27(9), 1123-1130. https://doi.org/10.1177/0146167201279005 
Buzsaki, G. (2004). Neuronal Oscillations in Cortical Networks. Science, 304(5679), 19261929. https://doi.org/10.1126/science.1099745

Chen, Y., \& Huang, X. (2015). Modulation of Alpha and Beta Oscillations during an n-back Task with Varying Temporal Memory Load. Frontiers in Psychology, 6, 2031. https://doi.org/10.3389/fpsyg.2015.02031

Cole, S., \& Voytek, B. (2019). Cycle-by-cycle analysis of neural oscillations. Journal of Neurophysiology, 122(2), 849-861. https://doi.org/10/gf5tf9

Cowan, N. (2001). The magical number 4 in short-term memory: A reconsideration of mental storage capacity. Behavioral and Brain Sciences, 24(1), 87-114. https://doi.org/10.1017/S0140525X01003922

Crespo-Garcia, M., Pinal, D., Cantero, J. L., Diaz, F., Zurron, M., \& Atienza, M. (2013). Working memory processes are mediated by local and long-range synchronization of alpha oscillations. Journal of Cognitive Neuroscience, 25(8), 1343-1357.https://doi.org/10.1162/jocn_a_00379

Daniel, T. A., Katz, J. S., \& Robinson, J. L. (2016). Delayed match-to-sample in working memory: A BrainMap meta-analysis. Biological Psychology, 120, 10-20. https://doi.org/10.1016/j.biopsycho.2016.07.015

Daume, J., Graetz, S., Gruber, T., Engel, A. K., \& Friese, U. (2017). Cognitive control during audiovisual working memory engages frontotemporal theta-band interactions. Scientific Reports, 7(1), 12585. https://doi.org/10.1038/s41598-017-12511-3

Daume, J., Gruber, T., Engel, A. K., \& Friese, U. (2017). Phase-Amplitude Coupling and Long-Range Phase Synchronization Reveal Frontotemporal Interactions during Visual Working Memory. The Journal of Neuroscience, 37(2), 313-322. https://doi.org/10.1523/JNEUROSCI.2130-16.2016 
de Vries, I. E. J., Driel, J. van, \& Olivers, C. N. L. (2017). Posterior $\alpha$ EEG Dynamics Dissociate Current from Future Goals in Working Memory-Guided Visual Search. Journal of Neuroscience, 37(6), 1591-1603. https://doi.org/10.1523/jneurosci.294516.2016

de Vries, I. E. J., Savran, E., van Driel, J., \& Olivers, C. N. L. (2019). Oscillatory Mechanisms of Preparing for Visual Distraction. Journal of Cognitive Neuroscience, 31(12), 1873-1894.https://doi.org/10.1162/jocn_a_01460

de Vries, I. E. J., van Driel, J., Karacaoglu, M., \& Olivers, C. N. L. (2018). Priority Switches in Visual Working Memory are Supported by Frontal Delta and Posterior Alpha Interactions. Cerebral Cortex, $\quad$ 28(11), $\quad$ 4090-4104. https://doi.org/10.1093/cercor/bhy223

Deiber, M.-P., Missonnier, P., Bertrand, O., Gold, G., Fazio-Costa, L., Ibanez, V., \& Giannakopoulos, P. (2007). Distinction between perceptual and attentional processing in working memory tasks: A study of phase-locked and induced oscillatory brain dynamics. Journal of Cognitive Neuroscience, 19(1), 158-172.

D’Esposito, M., \& Postle, B. R. (2015). The Cognitive Neuroscience of Working Memory. Annual Review of Psychology, 66(1), 115-142. https://doi.org/10.1146/annurevpsych-010814-015031

Donoghue, T., Haller, M., Peterson, E., Varma, P., Sebastian, P., Gao, R., ... Voytek, B. ((in press)). Parameterizing neural power spectra into periodic and aperiodic components. Nature Neuroscience.

Ellmore, T. M., Ng, K., \& Reichert, C. P. (2017). Early and late components of EEG delay activity correlate differently with scene working memory performance. Plos One, 12(10), e0186072. https://doi.org/10.1371/journal.pone.0186072 
Erickson, M. A., Smith, D., Albrecht, M. A., \& Silverstein, S. (2019). Alpha-band desynchronization reflects memory-specific processes during visual change detection. Psychophysiology, 56(11). https://doi.org/10.1111/psyp.13442

Eschmann, K. C. J., Bader, R., \& Mecklinger, A. (2018). Topographical differences of frontalmidline theta activity reflect functional differences in cognitive control abilities. Brain and Cognition, 123, 57-64. https://doi.org/10.1016/j.bandc.2018.02.002

Fell, J., \& Axmacher, N. (2011). The role of phase synchronization in memory processes. Nature Reviews Neuroscience, 12(2), 105-118. https://doi.org/10.1038/nrn2979

Foxe, J. J., \& Snyder, A. C. (2011). The Role of Alpha-Band Brain Oscillations as a Sensory Suppression Mechanism during Selective Attention. Frontiers in Psychology, 2. https://doi.org/10/chss8z

Fukuda, K., Mance, I., \& Vogel, E. K. (2015). Alpha Power Modulation and Event-Related Slow Wave Provide Dissociable Correlates of Visual Working Memory. The Journal of Neuroscience, 35(41), 14009-14016. https://doi.org/10.1523/jneurosci.500314.2015

Gao, C., Sun, J., Yang, X., \& Gong, H. (2018). Gender differences in brain networks during verbal Sternberg tasks: A simultaneous near-infrared spectroscopy and electroencephalography study. Journal of Biophotonics, 11(3). https://doi.org/10.1002/jbio.201700120

Gehrig, J., Michalareas, G., Forster, M.-T., Lei, J., Hok, P., Laufs, H., ... Kell, C. A. (2019). LowFrequency Oscillations Code Speech during Verbal Working Memory. The Journal of Neuroscience, 39(33), 6498-6512. https://doi.org/10.1523/JNEUROSCI.001819.2019

Gitelman, D. R., Penny, W. D., Ashburner, J., \& Friston, K. J. (2003). Modeling regional and psychophysiologic interactions in fMRI: The importance of hemodynamic 
deconvolution. NeuroImage, 19(1), 200-207. https://doi.org/10.1016/S10538119(03)00058-2

Griesmayr, B., Berger, B., Stelzig-Schoeler, R., Aichhorn, W., Bergmann, J., \& Sauseng, P. (2014). EEG theta phase coupling during executive control of visual working memory investigated in individuals with schizophrenia and in healthy controls. Cognitive, Affective, \& Behavioral Neuroscience, 14(4), 1340-1355. https://doi.org/10.3758/s13415-014-0272-0

Griesmayr, B., Gruber, W. R., Klimesch, W., \& Sauseng, P. (2010). Human frontal midline theta and its synchronization to gamma during a verbal delayed match to sample task. Neurobiology of Learning and Memory, 93(2), 208-215. https://doi.org/10.1016/j.nlm.2009.09.013

Grimault, S., Robitaille, N., Grova, C., Lina, J.-M., Dubarry, A.-S., \& Jolicœur, P. (2009). Oscillatory activity in parietal and dorsolateral prefrontal cortex during retention in visual short-term memory: Additive effects of spatial attention and memory load. Human Brain Mapping, 30(10), 3378-3392. https://doi.org/10/dk66tf

Harmony, T., Fernandez, T., Silva, J., Bernal, J., Diaz-Comas, L., Reyes, A., ... Rodriguez, M. (1996). EEG delta activity: An indicator of attention to internal processing during performance of mental tasks. International Journal of Psychophysiology, 24(1-2), 161-171. https://doi.org/10.1016/S0167-8760(96)00053-0

Heinrichs-Graham, E., \& Wilson, T. W. (2015). Spatiotemporal oscillatory dynamics during the encoding and maintenance phases of a visual working memory task. Cortex, 69, 121-130. https://doi.org/10.1016/j.cortex.2015.04.022

Heinz, A. J., \& Johnson, J. S. (2017). Load-Dependent Increases in Delay-Period Alpha-Band Power Track the Gating of Task-Irrelevant Inputs to Working Memory. Frontiers in Human Neuroscience, 11, 250. https://doi.org/10.3389/fnhum.2017.00250 
Herrmann, C. S., Fründ, I., \& Lenz, D. (2010). Human gamma-band activity: A review on cognitive and behavioral correlates and network models. Neuroscience \& $\begin{array}{lll}\text { Biobehavioral } & \text { Reviews, } & \text { 981-992), }\end{array}$ https://doi.org/10.1016/j.neubiorev.2009.09.001

Herrmann, C. S., Senkowski, D., \& Rottger, S. (2004). Phase-locking and amplitude modulations of EEG alpha: Two measures reflect different cognitive processes in a working memory task. Experimental Psychology, 51(4), 311-318. https://doi.org/10.1027/1618-3169.51.4.311

Honkanen, R., Rouhinen, S., Wang, S. H., Palva, J. M., \& Palva, S. (2015). Gamma Oscillations Underlie the Maintenance of Feature-Specific Information and the Contents of Visual Working Memory. Cerebral Cortex, 25(10), 3788-3801. https://doi.org/10.1093/cercor/bhu263

Howard, M. W., Rizzuto, D. S., Caplan, J. B., Madsen, J. R., Lisman, J., AschenbrennerScheibe, R., ... Kahana, M. J. (2003). Gamma Oscillations Correlate with Working Memory Load in Humans. Cerebral Cortex, 13(12), 1369-1374. https://doi.org/10/dbw5tp

Hsieh, L. T., Ekstrom, A. D., \& Ranganath, C. (2011). Neural oscillations associated with item and temporal order maintenance in working memory. The Journal of Neuroscience, 31(30), 10803-10810. https://doi.org/10.1523/jneurosci.082811.2011

Hsieh, L.-T., \& Ranganath, C. (2014). Frontal midline theta oscillations during working memory maintenance and episodic encoding and retrieval. NeuroImage, 85, Part 2, 721-729. https://doi.org/10.1016/j.neuroimage.2013.08.003

Hu, Z., Barkley, C. M., Marino, S. E., Wang, C., Rajan, A., Bo, K., ... Ding, M. (2019). Working Memory Capacity Is Negatively Associated with Memory Load Modulation of 
Alpha Oscillations in Retention of Verbal Working Memory. Journal of Cognitive Neuroscience, 1-13. https://doi.org/10.1162/jocn_a_01461

Ichihara-Takeda, S., Yazawa, S., Murahara, T., Toyoshima, T., Shinozaki, J., Ishiguro, M., ... Nagamine, T. (2015). Modulation of Alpha Activity in the Parieto-occipital Area by Distractors during a Visuospatial Working Memory Task: A Magnetoencephalographic Study. Journal of Cognitive Neuroscience, 27(3), 453463. https://doi.org/10.1162/jocn_a_00718

Ikkai, A., Blacker, K. J., Lakshmanan, B. M., Ewen, J. B., \& Courtney, S. M. (2014). Maintenance of relational information in working memory leads to suppression of the sensory cortex. Journal of Neurophysiology, 112(8), 1903-1915. https://doi.org/10.1152/jn.00134.2014

Itthipuripat, S., Wessel, J. R., \& Aron, A. R. (2013). Frontal theta is a signature of successful working memory manipulation. Experimental Brain Research, 224(2), 255-262. https://doi.org/10.1007/s00221-012-3305-3

Jensen, O., Gelfand, J., Kounios, J., \& Lisman, J. E. (2002). Oscillations in the alpha band (9$12 \mathrm{~Hz}$ ) increase with memory load during retention in a short-term memory task. Cerebral Cortex, 12(8), 877-882. https://doi.org/10.1093/cercor/12.8.877

Jensen, O., \& Mazaheri, A. (2010). Shaping Functional Architecture by Oscillatory Alpha Activity: Gating by Inhibition. Frontiers in Human Neuroscience, 4. https://doi.org/10.3389/fnhum.2010.00186

Jensen, O., \& Tesche, C. D. (2002). Frontal theta activity in humans increases with memory load in a working memory task. European Journal of Neuroscience, 15(8), 13951399.

Jerbi, K., Ossandón, T., Hamamé, C. M., Senova, S., Dalal, S. S., Jung, J., ... Lachaux, J.-P. (2009). Task-related gamma-band dynamics from an intracerebral perspective: 
Review and implications for surface EEG and MEG. Human Brain Mapping, 30(6), 1758-1771. https://doi.org/10.1002/hbm.20750

Johnson, J. S., Sutterer, D. W., Acheson, D. J., Lewis-Peacock, J. A., \& Postle, B. R. (2011). Increased Alpha-Band Power during the Retention of Shapes and Shape-Location Associations in Visual Short-Term Memory. Frontiers in Psychology, 2, 128. https://doi.org/10.3389/fpsyg.2011.00128

Jokisch, D., \& Jensen, O. (2007). Modulation of Gamma and Alpha Activity during a Working Memory Task Engaging the Dorsal or Ventral Stream. Journal of Neuroscience, 27(12), 3244-3251. https://doi.org/10/bh4bjm

Kambara, T., Brown, E. C., Jeong, J.-W., Ofen, N., Nakai, Y., \& Asano, E. (2017). Spatiotemporal dynamics of working memory maintenance and scanning of verbal information. Clinical Neurophysiology, 128(6), 882-891. https://doi.org/10.1016/j.clinph.2017.03.005

Kaplan, R., Bush, D., Bisby, J. A., Horner, A. J., Meyer, S. S., \& Burgess, N. (2016). Medial Prefrontal-Medial Temporal Theta Phase Coupling in Dynamic Spatial Imagery. Journal of Cognitive Neuroscience, 29(3), 507-519. https://doi.org/10.1162/jocn_a_01064

Kawasaki, M., \& Yamaguchi, Y. (2012). Individual visual working memory capacities and related brain oscillatory activities are modulated by color preferences. Frontiers in Human Neuroscience, 6, 318. https://doi.org/10.3389/fnhum.2012.00318

Kawasaki, M., \& Yamaguchi, Y. (2013). Frontal theta and beta synchronizations for monetary reward increase visual working memory capacity. Social Cognitive and Affective Neuroscience, 8(5), 523-530. https://doi.org/10.1093/scan/nss027

Khader, P. H., Jost, K., Ranganath, C., \& Rosler, F. (2010). Theta and alpha oscillations during working-memory maintenance predict successful long-term memory 
encoding. Neuroscience $\quad$ Letters, 468(3), 339-343. https://doi.org/10.1016/j.neulet.2009.11.028

Klimesch, W. (1999). EEG alpha and theta oscillations reflect cognitive and memory performance: A review and analysis. Brain Research Reviews, 29(2), 169-195.

Klimesch, W., Doppelmayr, M., Schwaiger, J., Auinger, P., \& Winkler, T. (1999). "Paradoxical" alpha synchronization in a memory task. Brain Research. Cognitive Brain Research, 7(4), 493-501. https://doi.org/10.1016/S0926-6410(98)000561

Klimesch, W., Sauseng, P., \& Hanslmayr, S. (2007). EEG alpha oscillations: The inhibitiontiming hypothesis. Brain Research Reviews, 53(1), 63-88. https://doi.org/10.1016/j.brainresrev.2006.06.003

Klimesch, W., Schimke, H., \& Pfurtscheller, G. (1993). Alpha frequency, cognitive load and memory performance. Brain Topography, 5(3), 241-251. https://doi.org/10.1007/BF01128991

Kosciessa, J. Q., Grandy, T. H., Garrett, D. D., \& Werkle-Bergner, M. (2020). Single-trial characterization of neural rhythms: Potential and challenges. NeuroImage, 206, 116331. https://doi.org/10/ggd4tx

Kotchoubey, B. (2002). Do Event-Related Brain Potentials Reflect Mental (Cognitive) Operations? Journal of Psychophysiology, 16(3), 129-149. https://doi.org/10.1027//0269-8803.16.3.129

Kottlow, M., Schlaepfer, A., Baenninger, A., Michels, L., Brandeis, D., \& Koenig, T. (2015). Pre-stimulus BOLD-network activation modulates EEG spectral activity during working memory retention. Frontiers in Behavioral Neuroscience, 9, 111. https://doi.org/10.3389/fnbeh.2015.00111 
Kulashekhar, S., Pekkola, J., Palva, J. M., \& Palva, S. (2016). The role of cortical beta oscillations in time estimation. Human Brain Mapping, 37(9), 3262-3281. https://doi.org/10.1002/hbm.23239

Kustermann, T., Rockstroh, B., Miller, G. A., \& Popov, T. (2018). Neural network communication facilitates verbal working memory. Biological Psychology, 136, 119-126. https://doi.org/10.1016/j.biopsycho.2018.05.018

Kwon, G., Lim, S., Kim, M. Y., Kwon, H., Lee, Y. H., Kim, K., ... Suh, M. (2015). Individual differences in oscillatory brain activity in response to varying attentional demands during a word recall and oculomotor dual task. Frontiers in Human Neuroscience, 9, 381. https://doi.org/10.3389/fnhum.2015.00381

Leijten, F. S. S., Huiskamp, G.-J. M., Hilgersom, I., \& van Huffelen, A. C. (2003). Highresolution Source Imaging in Mesiotemporal Lobe Epilepsy: A Comparison Between MEG and Simultaneous EEG. Journal of Clinical Neurophysiology, 20(4), 227. https://doi.org/10.1097/00004691-200307000-00001

Leszczyński, M., Fell, J., \& Axmacher, N. (2015). Rhythmic Working Memory Activation in the Human Hippocampus. Cell Reports, 13(6), 1272-1282. https://doi.org/10.1016/j.celrep.2015.09.081

Lindquist, M. A., Meng Loh, J., Atlas, L. Y., \& Wager, T. D. (2009). Modeling the hemodynamic response function in fMRI: Efficiency, bias and mis-modeling. NeuroImage, $\quad 45(1, \quad$ Supplement $\quad 1), \quad$ S187-S198. https://doi.org/10.1016/j.neuroimage.2008.10.065

Luck, S. J., \& Vogel, E. K. (1997). The capacity of visual working memory for features and conjunctions. Nature, 390(6657), 279-281. https://doi.org/10.1038/36846 
Luria, R., Balaban, H., Awh, E., \& Vogel, E. K. (2016). The contralateral delay activity as a neural measure of visual working memory. Neuroscience and Biobehavioral Reviews, 62, 100-108. https://doi.org/10.1016/j.neubiorev.2016.01.003

Mainy, N., Kahane, P., Minotti, L., Hoffmann, D., Bertrand, O., \& Lachaux, J. P. (2007). Neural correlates of consolidation in working memory. Human Brain Mapping, 28(3), 183-193. https://doi.org/10.1002/hbm.20264

Malmivuo, J. (2012). Comparison of the Properties of EEG and MEG in Detecting the Electric Activity of the Brain. Brain Topography, 25(1), 1-19. https://doi.org/10.1007/s10548-011-0202-1

Manza, P., Hau, C. L., \& Leung, H. C. (2014). Alpha power gates relevant information during working memory updating. The Journal of Neuroscience, 34(17), 5998-6002. https://doi.org/10.1523/jneurosci.4641-13.2014

Mapelli, I., \& Ozkurt, T. E. (2019). Brain Oscillatory Correlates of Visual Short-Term Memory Errors. Frontiers in Human Neuroscience, 13, 33. https://doi.org/10.3389/fnhum.2019.00033

Maurer, U., Brem, S., Liechti, M., Maurizio, S., Michels, L., \& Brandeis, D. (2015). Frontal midline theta reflects individual task performance in a working memory task. Brain Topography, 28(1), 127-134. https://doi.org/10.1007/s10548-014-0361-y

Medendorp, W. P., Kramer, G. F. I., Jensen, O., Oostenveld, R., Schoffelen, J.-M., \& Fries, P. (2007). Oscillatory Activity in Human Parietal and Occipital Cortex Shows Hemispheric Lateralization and Memory Effects in a Delayed Double-Step Saccade Task. Cerebral Cortex, 17(10), 2364-2374. https://doi.org/10/cttpk8

Meltzer, J. A., Negishi, M., Mayes, L. C., \& Constable, R. T. (2007). Individual differences in EEG theta and alpha dynamics during working memory correlate with fMRI responses across subjects. Clinical Neurophysiology, 118(11), 2419-2436. 
Meltzer, J. A., Zaveri, H. P., Goncharova, I. I., Distasio, M. M., Papademetris, X., Spencer, S. S., ... Constable, R. T. (2008). Effects of Working Memory Load on Oscillatory Power in Human Intracranial EEG. Cerebral Cortex, 18(8), 1843-1855. https://doi.org/10/bfmnb9

Michels, L., Bucher, K., Lüchinger, R., Klaver, P., Martin, E., Jeanmonod, D., \& Brandeis, D. (2010). Simultaneous EEG-fMRI during a Working Memory Task: Modulations in Low and High Frequency Bands. PLoS ONE, 5(4), e10298. https://doi.org/10.1371/journal.pone.0010298

Michels, L., Moazami-Goudarzi, M., Jeanmonod, D., \& Sarnthein, J. (2008). EEG alpha distinguishes between cuneal and precuneal activation in working memory. NeuroImage, $40(3)$, 1296-1310. https://doi.org/10.1016/j.neuroimage.2007.12.048

Moran, R. J., Campo, P., Maestú, F., Reilly, R. B., Dolan, R. J., \& Strange, B. A. (2010). Peak Frequency in the Theta and Alpha Bands Correlates with Human Working Memory Capacity. Frontiers in Human Neuroscience, 4. https://doi.org/10/fk9dfr

Morgan, H. M., Muthukumaraswamy, S. D., Hibbs, C. S., Shapiro, K. L., Bracewell, R. M., Singh, K. D., \& Linden, D. E. J. (2011). Feature integration in visual working memory: Parietal gamma activity is related to cognitive coordination. Journal of Neurophysiology, 106(6), 3185-3194. https://doi.org/10.1152/jn.00246.2011

Murphy, O. W., Hoy, K. E., Wong, D., Bailey, N. W., Fitzgerald, P. B., \& Segrave, R. A. (2019). Individuals with depression display abnormal modulation of neural oscillatory activity during working memory encoding and maintenance. Biological Psychology, 148, 107766. https://doi.org/10/ggh24j 
Muthukumaraswamy, S. (2013). High-frequency brain activity and muscle artifacts in MEG/EEG: A review and recommendations. Frontiers in Human Neuroscience, 7. https://doi.org/10.3389/fnhum.2013.00138

Myers, N. E., Walther, L., Wallis, G., Stokes, M. G., \& Nobre, A. C. (2015). Temporal dynamics of attention during encoding versus maintenance of working memory: Complementary views from event-related potentials and alpha-band oscillations. Journal of Cognitive Neuroscience, 27(3), 492-508. https://doi.org/10.1162/jocn_a_00727

Nenert, R., Viswanathan, S., Dubuc, D. M., \& Visscher, K. M. (2012). Modulations of ongoing alpha oscillations predict successful short-term visual memory encoding. $\begin{array}{lllll}\text { Frontiers in } & \text { Human }\end{array}$ https://doi.org/10.3389/fnhum.2012.00127

Oberauer, K., Lewandowsky, S., Awh, E., Brown, G. D., Conway, A., Cowan, N., ... Hurlstone, M. J. (2018). Benchmarks for models of short-term and working memory. Psychological Bulletin, 144(9), 885.

Ocklenburg, S., Friedrich, P., Schmitz, J., Schlüter, C., Genc, E., Güntürkün, O., ... Grimshaw, G. (2019). Beyond frontal alpha: Investigating hemispheric asymmetries over the EEG frequency spectrum as a function of sex and handedness. Laterality: Asymmetries of Body, Brain and Cognition, 24(5), 505-524. https://doi.org/10.1080/1357650x.2018.1543314

Okada, Y. C., \& Salenius, S. (1998). Roles of attention, memory and motor preparation in modulating human brain activity in a spatial working memory task. Cerebral Cortex, 8(1), 80-96. https://doi.org/10.1093/cercor/8.1.80

Okuhata, S., Kusanagi, T., \& Kobayashi, T. (2013). Parietal EEG alpha suppression time of memory retrieval reflects memory load while the alpha power of memory 
maintenance is a composite of the visual process according to simultaneous and successive Sternberg memory tasks. Neuroscience Letters, 555, 79-84. https://doi.org/10.1016/j.neulet.2013.09.010

Olsen, R. K., Rondina, R., Riggs, L., Meltzer, J. A., \& Ryan, J. D. (2013). Hippocampal and Neocortical Oscillatory Contributions to Visuospatial Binding and Comparison. Journal of Experimental Psychology-General, 142(4), 1335-1345. https://doi.org/10.1037/a0034043

Onton, J., Delorme, A., \& Makeig, S. (2005). Frontal midline EEG dynamics during working memory. $\quad$ Neurolmage, 27(2), 341-356. https://doi.org/10.1016/j.neuroimage.2005.04.014

Pae, C.-U. (2015). Why Systematic Review rather than Narrative Review? Psychiatry Investigation, 12(3), 417-419. https://doi.org/10.4306/pi.2015.12.3.417

Pahor, A., \& Jausovec, N. (2017). Multifaceted pattern of neural efficiency in working memory capacity. $\quad$ Intelligence, $\quad 65, \quad 23-34$. https://doi.org/10.1016/j.intell.2017.10.001

Palomaki, J., Kivikangas, M., Alafuzoff, A., Hakala, T., \& Krause, C. M. (2012). Brain oscillatory 4-35 Hz EEG responses during an n-back task with complex visual stimuli. Neuroscience $\quad$ Letters, $516(1), \quad$ 141-145. https://doi.org/10.1016/j.neulet.2012.03.076

Park, H., Kang, E., Kang, H., Kim, J. S., Jensen, O., Chung, C. K., \& Lee, D. S. (2011). Crossfrequency power correlations reveal the right superior temporal gyrus as a hub region during working memory maintenance. Brain Connectivity, 1(6), 460-472. https://doi.org/10.1089/brain.2011.0046 
Park, J. Y., Min, B. K., Jung, Y. C., Pak, H., Jeong, Y. H., \& Kim, E. (2013). Illumination influences working memory: An EEG study. Neuroscience, 247, 386-394. https://doi.org/10.1016/j.neuroscience.2013.05.016

Parvizi, J., \& Kastner, S. (2018). Promises and limitations of human intracranial electroencephalography. Nature Neuroscience, 21(4), 474-483. https://doi.org/10/gdcnmz

Pavlov, Y. G., \& Kotchoubey, B. (2017). EEG correlates of working memory performance in females. BMC Neuroscience, 18(1), 26. https://doi.org/10.1186/s12868-0170344-5

Payne, L., \& Sekuler, R. (2014). The Importance of Ignoring: Alpha Oscillations Protect Selectivity. Current Directions in Psychological Science, 23(3), 171-177. https://doi.org/10/f57hd7

Pesonen, M., Hämäläinen, H., \& Krause, C. M. (2007). Brain oscillatory 4-30 Hz responses during a visual n-back memory task with varying memory load. Brain Research, 1138, 171-177. https://doi.org/10.1016/j.brainres.2006.12.076

Poch, C., Campo, P., \& Barnes, G. R. (2014). Modulation of alpha and gamma oscillations related to retrospectively orienting attention within working memory. European Journal of Neuroscience, 40(2), 2399-2405. https://doi.org/10.1111/ejn.12589

Poch, C., Campo, P., Parmentier, F. B. R., Ruiz-Vargas, J. M., Elsley, J. V., Castellanos, N. P., ... del Pozo, F. (2010). Explicit processing of verbal and spatial features during letterlocation binding modulates oscillatory activity of a fronto-parietal network. Neuropsychologia, $\quad 48(13), \quad 3846-3854$. https://doi.org/10.1016/j.neuropsychologia.2010.09.015

Poch, C., Valdivia, M., Capilla, A., Hinojosa, J. A., \& Campo, P. (2018). Suppression of nolonger relevant information in Working Memory: An alpha-power related 
mechanism? Biological Psychology, 135, 112-116. https://doi.org/10.1016/j.biopsycho.2018.03.009

Postle, B. R. (2006). Working memory as an emergent property of the mind and brain. Neuroscience, $139(1)$ 23-38. https://doi.org/10.1016/j.neuroscience.2005.06.005

Proskovec, A. L., Heinrichs-Graham, E., \& Wilson, T. W. (2019). Load modulates the alpha and beta oscillatory dynamics serving verbal working memory. NeuroImage, 184, 256-265. https://doi.org/10.1016/j.neuroimage.2018.09.022

Proskovec, A. L., Wiesman, A. I., Heinrichs-Graham, E., \& Wilson, T. W. (2018). Beta Oscillatory Dynamics in the Prefrontal and Superior Temporal Cortices Predict Spatial Working Memory Performance. Scientific Reports, 8(1), 8488. https://doi.org/10/gdp4ww

Proskovec, A. L., Wiesman, A. I., Heinrichs-Graham, E., \& Wilson, T. W. (2019). Load effects on spatial working memory performance are linked to distributed alpha and beta oscillations. Human Brain Mapping. https://doi.org/10.1002/hbm.24625

Raghavachari, S., Kahana, M. J., Rizzuto, D. S., Caplan, J. B., Kirschen, M. P., Bourgeois, B., ... Lisman, J. E. (2001). Gating of human theta oscillations by a working memory task. The Journal of Neuroscience, 21(9), 3175-3183.

Rawle, C. J., Miall, R. C., \& Praamstra, P. (2012). Frontoparietal theta activity supports behavioral decisions in movement-target selection. Frontiers in Human Neuroscience, 6, 138. https://doi.org/10.3389/fnhum.2012.00138

Roberts, B. M., Hsieh, L. T., \& Ranganath, C. (2013). Oscillatory activity during maintenance of spatial and temporal information in working memory. Neuropsychologia, $51(2)$, 349-357. https://doi.org/10.1016/j.neuropsychologia.2012.10.009 
Román-López, T. V., Caballero-Sánchez, U., Cisneros-Luna, S., Franco-Rodríguez, J. A., Méndez-Díaz, M., Prospéro-García, O., \& Ruiz-Contreras, A. E. (2019). Brain electrical activity from encoding to retrieval while maintaining and manipulating information in working memory. Memory, $0(0)$, 1-16. https://doi.org/10.1080/09658211.2019.1620287

Rominger, C., Fink, A., Weiss, E. M., Schulter, G., Perchtold, C. M., \& Papousek, I. (2019). The propensity to perceive meaningful coincidences is associated with increased posterior alpha power during retention of information in a modified Sternberg $\begin{array}{llll}\text { paradigm. } & \text { Consciousness }\end{array}$ https://doi.org/10.1016/j.concog.2019.102832

Roux, F., \& Uhlhaas, P. J. (2014). Working memory and neural oscillations: Alpha-gamma versus theta-gamma codes for distinct WM information? Trends in Cognitive Sciences, 18(1), 16-25. https://doi.org/10.1016/j.tics.2013.10.010

Roux, F., Wibral, M., Mohr, H. M., Singer, W., \& Uhlhaas, P. J. (2012). Gamma-Band Activity in Human Prefrontal Cortex Codes for the Number of Relevant Items Maintained in Working Memory. Journal of Neuroscience, 32(36), 12411-12420. https://doi.org/10.1523/jneurosci.0421-12.2012

Sauseng, P., Klimesch, W., Doppelmayr, M., Pecherstorfer, T., Freunberger, R., \& Hanslmayr, S. (2005). EEG alpha synchronization and functional coupling during top-down processing in a working memory task. Human Brain Mapping, 26(2), 148-155. https://doi.org/10.1002/hbm.20150

Sauseng, P., Klimesch, W., Heise, K. F., Gruber, W. R., Holz, E., Karim, A. A., ... Hummel, F. C. (2009). Brain Oscillatory Substrates of Visual Short-Term Memory Capacity. Current Biology, 19(21), 1846-1852. https://doi.org/10.1016/j.cub.2009.08.062 
Schack, B., \& Klimesch, W. (2002). Frequency characteristics of evoked and oscillatory electroencephalic activity in a human memory scanning task. Neuroscience Letters, 331(2), 107-110. https://doi.org/10/b8b5kc

Scheeringa, R., Petersson, K. M., Oostenveld, R., Norris, D. G., Hagoort, P., \& Bastiaansen, M. C. M. (2009). Trial-by-trial coupling between EEG and BOLD identifies networks related to alpha and theta EEG power increases during working memory maintenance. $\quad$ NeuroImage, $\quad 44(3), \quad 1224-1238$. https://doi.org/10.1016/j.neuroimage.2008.08.041

Schneider, D., Goddertz, A., Haase, H., Hickey, C., \& Wascher, E. (2019). Hemispheric asymmetries in EEG alpha oscillations indicate active inhibition during attentional orienting within working memory. Behavioural Brain Research, 359, 38-46. https://doi.org/10.1016/j.bbr.2018.10.020

Schroeder, S. C. Y., Ball, F., \& Busch, N. A. (2018). The role of alpha oscillations in distractor inhibition during memory retention. European Journal of Neuroscience, 48(7), 2516-2526. https://doi.org/10.1111/ejn.13852

Seemuller, A., Muller, E. M., \& Rosler, F. (2012). EEG-power and -coherence changes in a unimodal and a crossmodal working memory task with visual and kinesthetic $\begin{array}{llll}\text { stimuli. Int } \quad \text { Psychophysiol, } & \text { 83(1), }\end{array}$ https://doi.org/10.1016/j.ijpsycho.2011.10.009

Segrave, R. A., Thomson, R. H., Cooper, N. R., Croft, R. J., Sheppard, D. M., \& Fitzgerald, P. B. (2010). Upper alpha activity during working memory processing reflects abnormal inhibition in major depression. Journal of Affective Disorders, 127(1-3), 191-198. https://doi.org/10/dnhjg7

Sharon, D., Hämäläinen, M. S., Tootell, R. B. H., Halgren, E., \& Belliveau, J. W. (2007). The advantage of combining MEG and EEG: Comparison to fMRI in focally stimulated 
visual cortex. $\quad$ NeuroImage, $\quad 36(4), \quad 1225-1235$. https://doi.org/10.1016/j.neuroimage.2007.03.066

Smyrnis, N., Protopapa, F., Tsoukas, E., Balogh, A., Siettos, C. I., \& Evdokimidis, I. (2014). Amplitude spectrum EEG signal evidence for the dissociation of motor and perceptual spatial working memory in the human brain. Experimental Brain Research, 232(2), 659-673. https://doi.org/10.1007/s00221-013-3774-z

Šoškić, A., Jovanović, V., Styles, S. J., Kappenman, E. S., \& Kovic, V. (2020). How to do better N400 studies: Reproducibility, consistency and adherence to research standards in the existing literature. https://doi.org/10.31234/osf.io/jp6wy

Spitzer, B., \& Blankenburg, F. (2012). Supramodal Parametric Working Memory Processing in Humans. The Journal of Neuroscience, 32(10), 3287-3295. https://doi.org/10.1523/JNEUROSCI.5280-11.2012

Spitzer, B., Fleck, S., \& Blankenburg, F. (2014). Parametric alpha- and beta-band signatures of supramodal numerosity information in human working memory. The Journal of Neuroscience, 34(12), 4293-4302. https://doi.org/10.1523/jneurosci.4580-13.2014

Stefan, H., Schüler, P., Abraham-Fuchs, K., Schneider, S., Gebhardt, M., Neubauer, U., ... Thierauf, P. (1994). Magnetic source localization and morphological changes in temporal lobe epilepsy: Comparison of MEG/EEG, ECoG and volumetric MRI in presurgical evaluation of operated patients. Acta Neurologica Scandinavica, 89(S152), 83-88. https://doi.org/10.1111/j.1600-0404.1994.tb05192.x

Steinbrink, J., Villringer, A., Kempf, F., Haux, D., Boden, S., \& Obrig, H. (2006). Illuminating the BOLD signal: Combined fMRI-fNIRS studies. Magnetic Resonance Imaging, 24(4), 495-505. https://doi.org/10.1016/j.mri.2005.12.034 
Stephane, M., Ince, N. F., Kuskowski, M., Leuthold, A., Tewfik, A. H., Nelson, K., ... Tadipatri, V. A. (2010). Neural oscillations associated with the primacy and recency effects of verbal working memory. Neuroscience Letters, 473(3), 172-177. https://doi.org/10.1016/j.neulet.2010.02.025

Sternberg, S. (1966). High-speed scanning in human memory. Science, 153(3736), 652654. https://doi.org/10/b4m7mh

Stewart, J. L., Coan, J. A., Towers, D. N., \& Allen, J. J. B. (2014). Resting and task-elicited prefrontal EEG alpha asymmetry in depression: Support for the capability model: Resting and task-elicited asymmetry. Psychophysiology, 51(5), 446-455. https://doi.org/10/f5xx63

Takase, R., Boasen, J., \& Yokosawa, K. (2019). Different roles for theta- and alpha-band brain rhythms during sequential memory. 2019 41st Annual International Conference of the IEEE Engineering in Medicine and Biology Society (EMBC), 17131716. https://doi.org/10/ggh338

Tallon-Baudry, C., Kreiter, A., \& Bertrand, O. (1999). Sustained and transient oscillatory responses in the gamma and beta bands in a visual short-term memory task in humans. Visual Neuroscience, 16(3), 449-459.

Todd, J. J., \& Marois, R. (2004). Capacity limit of visual short-term memory in human posterior parietal cortex. Nature, 428(6984), 751-754. https://doi.org/10.1038/nature02466

Trubutschek, D., Marti, S., Ojeda, A., King, J. R., Mi, Y., Tsodyks, M., \& Dehaene, S. (2017). A theory of working memory without consciousness or sustained activity. Elife, 6. https://doi.org/10.7554/eLife.23871

Trubutschek, D., Marti, S., Ueberschar, H., \& Dehaene, S. (2019). Probing the limits of activity-silent non-conscious working memory. Proceedings of the National 
Academy of Sciences of the United States of America, 116(28), 14358-14367. https://doi.org/10.1073/pnas.1820730116

Tuladhar, A. M., Huurne, N. ter, Schoffelen, J.-M., Maris, E., Oostenveld, R., \& Jensen, 0. (2007). Parieto-occipital sources account for the increase in alpha activity with working memory load. Human Brain Mapping, 28(8), 785-792. https://doi.org/10.1002/hbm.20306

van der Vinne, N., Vollebregt, M. A., van Putten, M. J. A. M., \& Arns, M. (2017). Frontal alpha asymmetry as a diagnostic marker in depression: Fact or fiction? A meta-analysis. NeuroImage: Clinical, 16, 79-87. https://doi.org/10/ggpqdc

van Dijk, H., van der Werf, J., Mazaheri, A., Medendorp, W. P., \& Jensen, O. (2010). Modulations in oscillatory activity with amplitude asymmetry can produce cognitively relevant event-related responses. Proceedings of the National Academy of Sciences of the United States of America, 107(2), 900-905. https://doi.org/10.1073/pnas.0908821107

van Ede, F. (2018). Mnemonic and attentional roles for states of attenuated alpha oscillations in perceptual working memory: A review. The European Journal of Neuroscience, 48(7), 2509-2515. https://doi.org/10.1111/ejn.13759

van Ede, F., Jensen, O., \& Maris, E. (2017). Supramodal Theta, Gamma, and Sustained Fields Predict Modality-specific Modulations of Alpha and Beta Oscillations during Visual and Tactile Working Memory. Journal of Cognitive Neuroscience, 29(8), 1455-1472. https://doi.org/10.1162/jocn_a_01129

Vandenbroucke, A. R. E., Sligte, I. G., de Vries, J. G., Cohen, M. X., \& Lamme, V. A. F. (2015). Neural Correlates of Visual Short-term Memory Dissociate between Fragile and Working Memory Representations. Journal of Cognitive Neuroscience, 27(12), 2477-2490. https://doi.org/10/ggp897 
Vissers, M. E., van Driel, J., \& Slagter, H. A. (2016). Proactive, but Not Reactive, Distractor Filtering Relies on Local Modulation of Alpha Oscillatory Activity. Journal of Cognitive Neuroscience, 28(12), 1964-1979. https://doi.org/10.1162/jocn_a_01017

Vogel, E. K., \& Machizawa, M. G. (2004). Neural activity predicts individual differences in visual working memory capacity. Nature, 428(6984), 748-751. https://doi.org/10.1038/nature02447

Wianda, E., \& Ross, B. (2019). The roles of alpha oscillation in working memory retention. Brain and Behavior, e01263. https://doi.org/10.1002/brb3.1263

Wilson, G. F., Swain, C. R., \& Ullsperger, P. (1999). EEG power changes during a multiple level memory retention task. International Journal of Psychophysiology, 32(2), 107-118. https://doi.org/10/dkvzj9

Wolff, M. J., Jochim, J., Akyürek, E. G., \& Stokes, M. G. (2017). Dynamic hidden states underlying working-memory-guided behavior. Nature Neuroscience, 20(6), 864. https://doi.org/10.1038/nn.4546

Worden, M. S., Foxe, J. J., Wang, N., \& Simpson, G. V. (2000). Anticipatory biasing of visuospatial attention indexed by retinotopically specific-band electroencephalography increases over occipital cortex. Journal of Neuroscience, 20(RC63), 1-6.

Xie, Y., Feng, Z., Xu, Y., Bian, C., \& Li, M. (2016). The different oscillation patterns of alpha band in the early and later stages of working memory maintenance. Neuroscience Letters, 633, 220-226. https://doi.org/10.1016/j.neulet.2016.09.047

Yin, J., Gao, Z., Jin, X., Ding, X., Liang, J., \& Shen, M. (2012). The neural mechanisms of percept-memory comparison in visual working memory. Biological Psychology, 90(1), 71-79. https://doi.org/10.1016/j.biopsycho.2012.02.023 
Zakrzewska, M. Z., \& Brzezicka, A. (2014). Working memory capacity as a moderator of load-related frontal midline theta variability in Sternberg task. Frontiers in Human Neuroscience, 8, 399. https://doi.org/10.3389/fnhum.2014.00399

Zhang, D., Zhao, H., Bai, W., \& Tian, X. (2016). Functional connectivity among multichannel EEGs when working memory load reaches the capacity. Brain Research, 1631, 101-112. https://doi.org/10.1016/j.brainres.2015.11.036

Zuure, M. B., Hinkley, L. B. N., Tiesinga, P. H. E., Nagarajan, S. S., \& Cohen, M. X. (2020). Multiple midfrontal thetas revealed by source separation of simultaneous MEG and EEG. BioRxiv, 2020.03.11.987040. https://doi.org/10/ggpvmr 